NBER WORKING PAPER SERIES

\title{
THE EQUILIBRIUM EFFECTS OF INFORMATION DELETION: EVIDENCE FROM CONSUMER CREDIT MARKETS
}

\author{
Andres Liberman \\ Christopher Neilson \\ Luis Opazo \\ Seth Zimmerman \\ Working Paper 25097 \\ http://www.nber.org/papers/w25097
NATIONAL BUREAU OF ECONOMIC RESEARCH
1050 Massachusetts Avenue
Cambridge, MA 02138
September 2018

\begin{abstract}
Previous drafts of this paper were circulated under the title "The Equilibrium Effects of Asymmetric Information: Evidence from Consumer Credit Markets." We thank Andrew Hertzberg, Amir Kermani, Neale Mahoney, Holger Mueller, Christopher Palmer, Philipp Schnabl, Johannes Stroebel, and numerous seminar participants for comments and suggestions. Sean Hyland and Jordan Rosenthal-Kay provided excellent research assistance. This research was funded in part by the Fama-Miller Center for Research in Finance and the Richard N. Rosett Faculty Fellowship at the University of Chicago Booth School of Business. We thank Sinacofi for providing the data. Luis Opazo declares that he is an employee of ABIF, which owns SINACOFI, the main data provider for this paper. The authors have no other relevant material or financial interests that relate to the research described in this paper. All errors and omissions are ours only. The views expressed herein are those of the authors and do not necessarily reflect the views of the National Bureau of Economic Research.
\end{abstract}

NBER working papers are circulated for discussion and comment purposes. They have not been peerreviewed or been subject to the review by the NBER Board of Directors that accompanies official NBER publications.

(C) 2018 by Andres Liberman, Christopher Neilson, Luis Opazo, and Seth Zimmerman. All rights reserved. Short sections of text, not to exceed two paragraphs, may be quoted without explicit permission provided that full credit, including $(\mathrm{C}$ notice, is given to the source. 
The Equilibrium Effects of Information Deletion: Evidence from Consumer Credit Markets Andres Liberman, Christopher Neilson, Luis Opazo, and Seth Zimmerman

NBER Working Paper No. 25097

September 2018, Revised August 2019

JEL No. D14,D82,G20

\begin{abstract}
$\underline{\text { ABSTRACT }}$
This paper studies the equilibrium effects of information restrictions in credit markets using a large-scale natural experiment. In 2012, Chilean credit bureaus were forced to stop reporting defaults for 2.8 million individuals ( $21 \%$ of the adult population). Using panel data on the universe of bank borrowers in Chile combined with the deleted registry information, we implement machine learning techniques to measure changes in the predictions lenders can make about default rates following deletion. Deletion lowers (raises) predicted default the most for poorer defaulters (non-defaulters) with limited borrowing histories. Using a difference-in-differences design, we show that individuals exposed to increases in predicted default reduce borrowing by $6.4 \%$ following deletion, while those exposed to decreases raise borrowing by $11.8 \%$. In aggregate, deletion reduces borrowing by $3.5 \%$. Taking the difference-in-difference estimates as inputs into a model of borrowing under adverse selection, we find that deletion reduces surplus under a variety of assumptions about lenders' pricing strategies.
\end{abstract}

Andres Liberman

New York University Stern School of Business

KMC 9-53

44 West Fourth Street

New York, NY

10012

aliberma@stern.nyu.edu

Christopher Neilson

Woodrow Wilson School

Princeton University

Firestone Library, Room A2H

Princeton, NJ 08544

and NBER

cneilson@princeton.edu
Luis Opazo

Chilean Banking Association

Lopazo@abif.cl

Seth Zimmerman

Booth School of Business

University of Chicago

5807 S. Woodlawn Avenue

Chicago, IL 60637

and NBER

seth.zimmerman@chicagobooth.edu

A data appendix is available at http://www.nber.org/data-appendix/w25097 


\section{Introduction}

Many countries have institutions that limit the information available to consumer lenders. For example, in 2007 , over $90 \%$ of countries with credit bureaus also had provisions that erased defaults after set periods of time (Elul and Gottardi 2015). Other forms of information limits include restrictions on the types of past borrowing outcomes and demographic variables that can be used to inform future lending decisions, and onetime purges of default records. The stated motivation for these policies is often that allowing lenders access to certain kinds of information unfairly reduces borrowing opportunities for individuals with past defaults (Miller 2003, Steinberg 2014), who may be disproportionately drawn from disadvantaged groups or have suffered from a negative past shock such as a natural disaster, an economic downturn, or a health event.

Several recent empirical studies confirm that deleting default records increases borrowing for beneficiaries (Bos and Nakamura 2014, González-Uribe and Osorio 2014, Herkenhoff, Phillips and Cohen-Cole 2016, Liberman 2016, Dobbie, Goldsmith-Pinkham, Mahoney and Song 2016). ${ }^{1}$ However, the implications these institutions have for aggregate lending and the distribution of access to credit depend not just on how they affect the beneficiaries of deletion, but on the information asymmetries they induce in consumer credit markets and the equilibrium responses by lenders (Akerlof 1970, Jaffee and Russell 1976, Stiglitz and Weiss 1981). Individuals whose credit information is deleted benefit if lenders perceive them as more willing or able to repay their loans. But this gain may come at a cost to the non-defaulters with whom defaulters are pooled. In aggregate, the effects of information-limiting institutions depend on the tradeoff between these two groups.

This paper exploits a large-scale, country-wide policy change to evaluate the effects of deleting credit information on consumer credit markets. In February 2012, the Chilean Congress passed Law 20,575 (henceforth, the "policy change"), which forced all credit bureaus operating in the country to stop reporting individual-level information on defaults. The policy change affected information for all individuals whose defaults as of December 2011 added up to less than 2.5 million Chilean pesos (CLP; roughly USD $\$ 5,000$ ), a group that made up $21 \%$ of all Chilean adults and $84 \%$ of all bank borrowers in default at the time of implementation. After the deletion, credit bureau information no longer distinguished individuals with deleted records from those with no defaults. The policy change was a one-time deletion and did not affect how subsequent defaults were recorded. Three years after the deletion, the count of individuals reported as in

\footnotetext{
${ }^{1}$ See also Musto (2004) and Brown and Zehnder (2007).
} 
default in the credit bureau had nearly returned to its pre-deletion level and was still rising.

We combine the policy change with administrative data that track bank outcomes and credit bureau data for the universe of bank borrowers in Chile. We begin by showing that borrowing for defaulters rises relative to borrowing for non-defaulters following the policy change. This finding is consistent with previous work on the effects of information deletion. However, it is uninformative about the aggregate effects of deletion because it reflects a combination of gains for defaulters and losses for non-defaulters. The empirical challenge in measuring aggregate effects is to construct counterfactuals for how consumer credit would have evolved for defaulters and non-defaulters in the absence of the policy change.

Our approach is to identify individuals for whom the deletion of default records from credit bureaus either raises or lowers predictions about future bank default, and to compare the change in borrowing for each group to the change in borrowing for individuals whose predicted bank default rates are unchanged. We are able to do this because we observe credit bureau defaults after the policy change, when banks can no longer do so. Intuitively, banks' credit supply decisions are likely to be correlated with predicted bank default rates. ${ }^{2}$ We use machine learning techniques to generate two sets of predictions about borrowers' expected probability of bank default. The first uses both bank borrowing data and credit bureau records, while the second uses only the bank borrowing data and not the deleted credit bureau records. Eliminating credit bureau data reduces both in- and out-of-sample log likelihoods of observed values given predictions, and produces systematic overestimates of bank default probabilities for borrowers without defaults and underestimates for borrowers with defaults.

We define exposure to the policy as percent increase in predicted bank default following deletion. Because credit bureau non-defaulters outnumber credit bureau defaulters, exposure is positive (i.e., predicted bank defaults rise) for $61 \%$ of the population. The individuals with the largest exposure borrow small amounts and do not have bank or non-bank defaults. They are on average poorer and less likely to own homes. These individuals resemble the borrowers for whom predicted default falls most dramatically, except that they do not show up on the credit bureau as in default. In contrast, predicted bank default does not change after deletion for individuals who borrow large amounts with higher rates of bank default.

Our exposure measure forms the basis of a difference-in-differences analysis. We use snapshots of borrower and credit bureau data at six month intervals leading up

\footnotetext{
${ }^{2}$ Dobbie, Liberman, Paravisini and Pathania (2018) provides evidence consistent with this claim.
} 
to and including the December 2011 snapshot to identify groups of borrowers who would have been exposed to positive, negative, and zero changes in default predictions had deletion taken place at that time. We use interactions between the predicted exposure variables and a dummy equal to one for cohorts exposed to the actual deletion policy-the December 2011 snapshot-to estimate the effects of deletion in the positiveand negative-exposure group relative to the zero-exposure group. This exercise recovers the effects of deletion on borrowing in aggregate under the assumptions that, a) borrowing trends in the positive, negative, and zero exposure groups would have evolved in parallel in the absence of the policy, and b) that the policy does not affect borrowing levels in the zero-exposure group.

We find that quantities borrowed by the negative- and positive-exposure groups move in parallel to the zero exposure group during the pre-deletion period. Following deletion, borrowing jumps up by $11.7 \%$ for the group exposed to decreases in predicted default (on a baseline mean of $\$ 141,000$ CLP) and falls by $6.4 \%$ for the group exposed to increases in predicted default (on a baseline mean of $\$ 215,000$ CLP). Lenders' predictions of default fall by $29 \%$ in the former group and rise by $22 \%$ in the latter, corresponding to elasticities of lending to predicted default of -0.40 and -0.29 in the positive and negative exposure groups, respectively. Because more borrowers are exposed to increases in predicted bank default than to decreases, these estimates mean that the aggregate effect of deletion across the two groups was to reduce borrowing by $3.5 \%$. The total value of the reduction in borrowing is about $\$ 20$ billion CLP over a six-month period, or $\$ 40$ million USD. Aggregate declines are largest as a share of borrowing for lower-income borrowers: borrowing drops by $4.2 \%$ for lower-income individuals and by $3.7 \%$ for individuals without mortgages. Repeating our differencein-difference analysis with actual (realized) default as the dependent variable shows that bank defaults increase as quantity decreases in both markets, although the effects are not statistically significant at conventional levels.

We evaluate the assumption that borrowing is unchanged for the zero-exposure group using a supplemental difference-in-differences analysis. We compare borrowing for defaulters in the zero-exposure group above the deletion cutoff-whose information was not deleted- to borrowing for below-threshold borrowers in the zero-exposure group- whose information was deleted. We find that deletion did not affect borrowing for the individuals in the zero-exposure group around the cutoff. In contrast, as expected, negative exposure borrowers below the threshold increase their borrowing significantly after the policy change. ${ }^{3}$

\footnotetext{
${ }^{3}$ There are no positive exposure borrowers with defaults close to the policy threshold, because individ-
} 
Though deletion reduces borrowing in aggregate, it could still raise total surplus if the individuals for whom borrowing rises value that borrowing more relative to costs than those for whom it falls. To study the effects of pooling high- and low-cost submarkets following the deletion of differentiating information we use a simple framework that takes an unraveling model in the style of Akerlof (1970) and Einav, Finkelstein and Cullen (2010) as a baseline. In the model, the effect of deletion on total surplus is ambiguous and depends on the demand and cost curves for high- and low-cost borrowers. We use the estimates from our difference-in-differences analysis to construct these curves, mapping borrowers with negative exposure to the high-cost market and borrowers with positive exposure to the low-cost market. In a baseline scenario with average cost pricing we find that pooling increases total surplus losses from adverse selection by $66 \%$ relative to the no-pooling equilibrium, a result that holds qualitatively over a wide range of possible markups over rates. Because deletion may have dynamic welfare effects or welfare effects outside of the credit markets, we view our findings as measures of the costs of providing insurance and benefits outside the credit market. ${ }^{4}$

In the final section of the paper, we use our procedure to study the effects of two counterfactual policies that limit information available to lenders: deleting bank default records in addition to credit bureau default records, and deleting information on gender (Munnell, Tootell, Browne and McEneaney 1996, Blanchflower, Levine and Zimmerman 2003, Pope and Sydnor 2011). Deleting additional default information increases the spread of changes in predicted bank default, with bigger gains for winners and losses for losers than in the policy as implemented. Deleting information on gender increases predicted bank default disproportionately for women. The common theme is that the costs of deletion fall mostly on individuals observably similar to the intended beneficiaries.

This paper contributes to a broader literature on the empirics of asymmetric information. Our finding that deleting information reduces overall borrowing and that costs fall most heavily on non-defaulters who resemble defaulters is similar to Agan and Starr (2017), which shows that restricting information on criminal records in job applications reduces callback rates for black applicants. We show how a machine learning approach can identify individuals affected by deletion policies, and develop a framework that

uals near the policy threshold are in default.

${ }^{4}$ For example, periodic information deletion may help insure against the ex ante 'reclassification' risk of defaulting and losing access to credit markets (Handel, Hendel and Whinston 2015), or may induce externalities in labor markets (Bos, Breza and Liberman 2018, Herkenhoff et al. 2016, Dobbie et al. 2016). See also Clifford and Shoag (2016), Bartik and Nelson (2016), Cortes, Glover and Tasci (2016), and Kovbasyuk and Spagnolo (2018). 
can be used to evaluate welfare effects.

We also contribute to a literature that uses machine learning to explore treatment effect heterogeneity given access to many possible mediating variables (Athey and Imbens 2016, Athey and Wagner 2017), and to generate counterfactuals that allow for causal inference where no credible experiment exists (Burlig, Knittel, Rapson, Reguant and Wolfram 2017). ${ }^{5}$ In contrast to this work, we focus on measures of predicted average costs that are theoretically-motivated as the key determinant of heterogeneous treatment effects. This reduces the set of causal parameters required to apply our approach in other settings from a potentially large number of heterogeneous effects defined across interactions of mediator variables to a single set of elasticities. Our approach complements the 'big data' that is increasingly prevalent in credit markets and other settings (Petersen and Rajan 2002, Einav and Levin 2014).

\section{Empirical setting}

\subsection{Formal consumer credit and credit information in Chile}

In Chile, formal consumer credit is supplied by banks and by other non-bank financial intermediaries, most notably department stores. As of December 2011 there were 23 banks operating in Chile, including one state-owned and 11 foreign-owned institutions, which had issued approximately $\$ 23$ billion in non-housing consumer credit (i.e., credit cards, overdraft credit lines, and unsecured term loans). ${ }^{6}$ As of the same month, the 9 largest non-banking lenders (all department stores) had a total consumer credit portfolio of approximately $\$ 5$ billion. Although banks issue more credit, the number of department store borrowers is larger (14.7 million active non-bank credit cards, of which 5.4 million recorded a transaction during that month, versus 3.8 million consumer credit bank borrowers). ${ }^{7}$

Banks (and non-bank lenders) rely on defaults reported in the credit bureau to run credit checks of potential borrowers (Cowan and De Gregorio 2003, Liberman 2016). Defaults reported to the credit bureau include bank and non-bank debt, as well as other

\footnotetext{
${ }^{5}$ See Varian (2016) or Mullainathan and Spiess (2017) for a review. Several other papers employ machine learning techniques to study credit markets. These include Huang, Chen and Wang (2007), Khandani, Kim and Lo (2010) and Fuster, Goldsmith-Pinkham, Ramadorai and Walther (2017). These papers focus on using machine learning techniques to improve cost prediction. In contrast, we use ML techniques to study the effects of actual and counterfactual policy changes on borrowing.

${ }^{6}$ All information in this paragraph is publicly available through the local banking regulator's website, www.sbif.cl.

${ }^{7}$ Chile's population is approximately 17 million.
} 
obligations such as bounced checks and utility bills. Importantly, banks are required by law to disclose their borrowers' outstanding balance and defaults to the banking regulator (SBIF), who then makes this information available only to banks. As a result, banks may learn a borrower's total bank debt and bank defaults, but may only observe reported defaults from non-banks (i.e., cannot access non-bank debt balances). In turn, non-banks can only learn an individuals' bank and non-bank defaults from the credit bureau, but not the level of bank or non-bank consumer credit.

\subsection{The policy change}

In early 2012, the Chilean Congress passed Law 20,575 to regulate credit information. ${ }^{8}$ The bill included a one-time "clean slate" provision by which credit bureaus would stop sharing information on individuals' delinquencies that were reported as of December 2011. This provision affected only borrowers whose total defaults, including bank and non-bank debts, added up to at most 2.5 million pesos. According to press reports, the provision was a way to alleviate alleged negative consequences of the February 2010 earthquake, which had caused large damage to property and had ostensibly forced a number of individuals into financial distress. The Chilean Congress had already enacted a similar law that forced credit bureaus to stop reporting information on past defaults in 2002. Nevertheless, this new "clean-slate" was marketed as a one-time change, and indeed, all new defaults incurred after December 2011 were subsequently subject to the regular treatment and reported by credit bureaus.

Following the passage and implementation on February 2012 of Law 20,575, credit bureaus stopped sharing information on defaults for roughly 2.8 million individuals, approximately $21 \%$ of the 13 million Chileans older than 15 years old. ${ }^{9}$ In effect, this means that individuals who were in default on any bank or non-bank credit as of December 2011 for a consolidated amount below 2.5 million pesos appeared as having no defaults after the passage of the law. This is shown in Figure 1, where we plot the time series of the number of individuals in our data with any positive default reported through credit bureaus as of the last day of each semester (ending in June or December). ${ }^{10}$ The figure shows a large reduction in the number of individuals with any defaults as of June 2012, after the policy change, relative to December $2011 .{ }^{11}$ Interestingly,

\footnotetext{
${ }^{8}$ See http:/ / www.leychile.cl/Navegar?idNorma=1037366.

${ }^{9}$ Figure taken from press reports of the "Primer Informe Trimestral de Deuda Personal", U. San Sebastian.

${ }^{10}$ Due to data constraints, our data is limited to individuals who were present in the regulatory banking dataset prior to the passage of Law 20,575.

${ }^{11}$ There is no evidence of an aggregate increase in defaults following the February 2010 earthquake.
} 
the figure shows a sharp increase in the number of affected individuals in the following semesters until December 2015, the last semester in our data. This is consistent with the fact that the policy was a one-time change, as future defaults were recorded and reported by credit bureaus, as well as with the fact that many individuals whose defaults were no longer reported did default on new obligations.

The policy change modified the information that lenders, bank and non-bank, could obtain on defaults at other lenders. After the policy change, non-bank lenders could no longer verify any type of defaults, while banks could not observe whether individuals had defaulted on non-bank debt. However, banks could still verify whether an individual had bank defaults because the banking regulator's data was not subject to the policy change. Thus, the policy change induced a sharp information asymmetry between the banking industry as a whole and its borrowers, rather than creating asymmetries in the information available to each bank with respect to its borrowers.

The median interest rate charged to small borrowers rose following deletion. Figure 2 plots median interest rates for small and large consumer loans before and after the deletion. We observe a 5.3 percentage point increase in rates in the small loan market, a $20 \%$ rise from a base of $26 \%$. Rates continue to rise following the policy change, reaching almost 35\% (30\% above the base pre-policy rate) by the fourth quarter following implementation. We do not observe changes in rates for larger borrowing amounts, which suggests that the effects we see are not driven by coincident changes in other determinants of borrowing rates. We show below that on average most new borrowing is done by borrowers with no defaults. This means that the median new loan can be thought of as belonging to this market.

\subsection{Data and summary statistics}

We obtain from Sinacofi, a privately owned Chilean credit bureau, individual-level panel data at the monthly level on the debt holdings and repayment status for the universe of bank borrowers in Chile from April 2009 until 2014. Sinacofi has access to the banking data that are not available to other credit bureaus because Sinacofi's only clients are banks. Sinacofi merged the data to measures of consolidated defaults from the credit registry. We observe registry data at six month intervals, in June and Decem-

ber of each year. As is typical in most empirical research on consumer credit, microdata do not include interest rates or other contract terms.

We use these data to build a panel dataset that links snapshots of defaults as reported to the credit bureau to borrowing outcomes. We use the six credit bureau snap- 
shots from December 2009 through December 2011. We link each snapshot to bank borrowing and default outcomes over the six month period beginning two months after the snapshot (i.e., the six month interval beginning in February for the December snapshots, and the six-month interval beginning in August for the June snapshot). This alignment corresponds to the timing of the deletion policy, which took place in February 2012 based on the December 2011 credit bureau default records.

Table 1 reports summary statistics for these data. The first column is the full sample, which includes all individuals who show up in the borrowing data. There are 23 million person-time period observations from 5.6 million individuals in the dataset. $37 \%$ of borrowers in our dataset have a positive value of credit bureau defaults, with an average value in default of $\$ 554,500$ CLP. $31 \%$ of the population, or $84 \%$ of all defaulters, have a default amount strictly between 0 and $\$ 2.5$ million CLP, and are eligible for deletion. Figure 3 presents a histogram of the default amount as of December 2011 for all individuals and for individuals with positive defaults. We observe deletion for $29 \%$ of all individuals in the December 2011 cohort. The two percent gap between our calculated deletion eligibility rate and observed deletion rate is due to rare default types that are not included in the consolidated measure we observe. Conditional on eligiblity for deletion, the average consolidated amount in default is $\$ 172,250$ CLP.

The average bank debt balance for consumers is $\$ 7.8$ million CLP. Unsecured consumer lending accounts for $28 \%$ of all debt, for an average of $\$ 2.2$ million CLP. Mortgage debt accounts for the majority of the remainder. The average bank default balance (defined as debt on which payments are at least 90 days overdue) across all borrowers is $\$ 338,090 \mathrm{CLP}$, or $12 \%$ of the overall debt balance. For borrowers eligible for deletion of defaults, this average is $\$ 147,460$. Comparing bank default balances to credit bureau default balances shows that deletion eliminates banks' access to $15 \%$ $(=100 \times(1-147 / 172))$ of the default amount among individuals whose balances in default falls below the deletion threshold.

We do not directly observe new borrowing or repayment. Thus, we define new consumer borrowing as any increase in an individual's consumer debt balance of at least $10 \%$ month over month, and the amount of new consumer borrowing as an indicator for new borrowing times the amount of the increase. In the full sample, 30\% of consumers take out at least one new consumer loan in the six month period following each credit snapshot. The average amount of new borrowing is $\$ 184,000$ CLP. We define new bank defaults analogously using borrowers' bank default balances. $17 \%$ of customers have a new bank default, with an average default amount of $\$ 37,000$ CLP. In our analysis of the effects of information deletion we focus on new consumer borrowing as the outcome of 
interest as defaults are most costly to lenders for uncollateralized borrowing.

The average age in our sample is 44 , and $44 \%$ of borrowers are female. Our data identify borrowers' socioeconomic status for $10 \%$ of individuals overall. These data, which were collected by banks, divide individuals into five groups by socioeconomic background. We use these data to generate predictions of socioeconomic status for all individuals in the sample using a machine learning approach. We describe this process in Appendix B. In our empirical analysis we split our sample by this predicted SES categorization. One strong predictor of SES classification is whether or not an individual has a home mortgage. We split by this categorization as well.

The second column of Table 1 describes our main analysis sample. We focus on borrowers who have a positive debt balance six months prior to the credit snapshot and consolidated default of $\$ 2.5$ million CLP or less, including zero values. This group accounts for $97 \%$ of individuals and $95 \%$ of observations. The restriction on debt balances allows us to define a consistent sample across time. Without it, the structure of our data generates spurious increases in mean borrowing over time. This occurs because individuals are included in our sample only if they borrow at some point between 2009 and 2014. An individual with a zero debt balance in 2009 must borrow in the future; otherwise, she would not be included in the data. Subsetting on individuals with positive debt balances at baseline addresses this issue. ${ }^{12}$ The restriction to consolidated defaults of \$2.5 million CLP or less lets us focus on the part of the credit market where available information changed. Lenders were able to observe consolidated defaults above $\$ 2.5$ million CLP both before and after the cutoff. Demographics and borrowing in the panel sample are similar to the full dataset.

The third column of Table 1 describes the sample of individuals with positive borrowing. As we discuss in the next section, this is the sample we use for constructing cost predictions. They tend to be richer, and have much lower current default balances relative to overall borrowing ( $0.01 \mathrm{vs} 0.09$ in the full panel). Their rates of future bank default are also somewhat lower (0.05 vs. 0.08 in the full panel).

\footnotetext{
${ }^{12}$ An alternate approach would be to take the population of all Chileans, irrespective of borrowing, as the sample. We do not have access to data on non-borrowers.
} 


\section{Equilibrium effects of information deletion}

\subsection{The effects of deletion for defaulters relative to non-defaulters}

We first report how borrowing and predicted bank default change for individuals with deleted credit bureau default records relative to individuals without deleted records. Using the full sample of borrower data in each credit bureau snapshot, we estimate difference-in-differences specifications that interact the individual's cohort relative to deletion with an indicator variable for a positive default on the credit bureau snapshot. The left panel of Figure 4 reports estimates of this specification when the dependent variable is the log of predicted bank default. We construct predictions of bank debt defaults in the next 6 months using a machine learning procedure that we detail below. This variable is equal to the (log) prediction using credit bureau defaults in the pre-deletion period and the prediction that excludes these records in the post-deletion period. The log difference in bank default predictions for credit bureau defaulters relative to credit bureau non-defaulters is steady in the year leading up to deletion, then falls by 0.66 after deletion, corresponding to a $52 \%$ decline in banks' default expectations for defaulters relative to non-defaulters.

The right panel of Figure 4 reports estimates when the dependent variable is new consumer borrowing. Borrowing is steady in the year leading up to deletion. In the six months following deletion borrowing for defaulters rises by just over $\$ 41,000$ CLP relative to borrowing for non-defaulters. This is $46 \%$ of the base-period borrowing of $\$ 88,000$ CLP for defaulters.

Our findings in this section imply that the deletion of credit bureau defaults raises borrowing for the beneficiaries of deletion relative to non-beneficiaries. However, this estimate reflects a combination of gains for defaulters and losses for non-defaulters, and cannot be interpreted as a causal estimate of the aggregate effect of the deletion of credit information on consumer borrowing. Next, we present our empirical strategy that makes use of changes to banks' default predictions in order to estimate the causal effects of the deletion of information.

\subsection{The causal effects of deletion on consumer borrowing}

\subsubsection{Constructing bank default predictions}

Deletion policies coarsen the information set that lenders can use to make predictions about their borrowers' expected repayment. In this section we estimate how this shock to the information set changes the predictions banks can make about future bank de- 
fault. We take a machine learning approach that describes changes in default predictions using a random forest (Mullainathan and Spiess 2017). The intuition underlying this approach is that banks make lending decisions by dividing potential borrowers into groups based on observable characteristics, and making predictions about future repayment within each group (Agarwal, Chomsisengphet, Mahoney and Stroebel 2018). We have access to borrowers' observable characteristics but do not observe banks' grouping choices. The random forest repeatedly chooses sets of possible predictor variables at random and constructs a regression tree using those predictors. Each tree iteratively splits by the explanatory variables, choosing splits to maximize in-sample predictive power. The random forest obtains predictions by averaging over predictions from each tree. One way to think about this process in our context is as averaging over different guesses about which variables banks might use to classify borrowers. When predicting default outcomes we focus on the sample of individuals who have new borrowing over that same period. We make this restriction because the goal of the exercise is to recover cost predictions for market participants.

We build each tree in our random forest by choosing variables at random from a set of 15 possible predictors. These consist of two lags (relative to the time of policy implementation) of new quarterly consumer borrowing, new quarterly total borrowing, consumer borrowing balance, secured debt balance, average cost, and available credit line, as well as a gender indicator. For pre-policy predictions, the set of variables also includes the credit bureau default data. We set the number of trees in a forest to 150 . Predictive power is not sensitive to other choices in this range. We choose other model parameters (how many variables to select for inclusion in each tree and the minimum number of observations in a terminal node in the tree) using a cross-validation procedure. For comparison, we also construct predictions using two alternate methods: a logistic LASSO and a näive Bayes classifier. See Appendix B for details on these approaches.

For each method, we construct two sets of predictions. The first set uses training data from the same registry cross-section as the outcome data. These predictions correspond to the best guess a lender can make about default outcomes using data available to them at the time of the loan. For this set of predictions, differences between predicted default with and without the default information depend on differences in the average default rate in each submarket in the market equilibrium prior to the reform, potentially time-varying shocks to credit demand, which move individuals with different covariate values along their cost curves, and endogenous responses to the pooling policy (in the post-pooling time period). 
To estimate the causal effects of the deletion on borrowing outcomes, we need to isolate variation in predicted default due to supply-side price shocks. Our second set of predictions helps us do this. This set of predictions uses training data from the December 2009 credit bureau default cross section to generate predictions for all other cross sections. Conditional on covariates, these predictions do not vary across cohorts in the remaining data, and therefore do not reflect the effects of time-varying demand shocks. They use only data from before pooling took place, so they do not reflect endogenous reponses to information deletion.

Based on this second set of predictions, we define exposure $E_{i}$ for borrower $i$ as the percentage change in predicted default rate due to deletion. Our empirical analysis splits borrowers into positive-, negative-, and zero-exposure groups, and tracks how contemporaneous default predictions and quantities borrowed change in these groups following deletion. We construct both types of predictions using a training sample consisting of $10 \%$ of the observations in the relevant snapshot. We exclude the December 2009 data from our difference-in-differences analysis in all specifications, and exclude training data from our default outcome analysis.

Table 2 compares in- and out-of-sample log likelihood measures for the random forest to those from other prediction methods. We present separate estimates for predictors trained in the pre-period and those trained contemporaneously. The contemporaneous random forest predictions have in-sample (out-of-sample) log likelihood values of $-0.173(-0.295)$ when including registry information. Without registry information, these values fall to $-0.177(-0.305)$. The pre-period random forest predictions have slightly higher log likelihoods in both the training and testing sample, with a similar percentage decline from dropping registry information. Random forest predictions outperform the näive Bayes and logistic LASSO predictions.

\subsubsection{The distribution of exposure to changes in predicted default}

In addition to reducing explanatory power, deletion affects the distribution of bank default predictions across credit bureau defaulters and non-defaulters. We describe these changes in Figures 5 and 6. We focus on predictions trained in pre-period data, but results are very similar using the predictions based on contemporaneous data.

The upper panel of Figure 5 shows the means of predictions made without default information within bins defined by values of the predictions that include default information. We split the sample by credit bureau default status. For individuals without defaults, deletion increases predicted default on average (points are above the 45-degree 
line). For individuals with defaults, deletion reduces default predictions (points are below the 45-degree line).

The lower panel of Figure 5 shows that predictions with and without deleted default information both track observed default across the distribution of realized default, on average. Default predictions slightly underpredict default at the bottom and middle of the default distribution, and overpredict at the top. As shown in the lower-left panel of the graph, differences in observed outcomes between borrowers with and without defaults tend to be small conditional on the full-information prediction. There are almost no borrowers with defaults at the bottom of the full-information predicted default distribution, and few borrowers without defaults at the very top. In the deleted information predictions (right panel), defaulters shift towards the bottom of the distribution and non-defaulters towards to the top. Conditional on the predicted default, defaulters have higher costs going forward.

Figure 6 explores the distribution of changes in predicted values from deletion in more detail. For each individual, exposure $E_{i}$ is the percentage change in default prediction caused by deletion. The upper panel of Figure 6 plots the density of $E_{i}$ by default status using predictions from the pre-period training set. For non-defaulters, predicted default rises for $89 \%$ of borrowers, with an average increase of $29 \%$. For defaulters, predicted default falls for $95 \%$ of borrowers, with an average drop of $32 \%$. The exposure distribution for defaulters is bimodal, with one mode at zero and the other centered near a decline of $75 \%$. More borrowers are non-defaulters than defaulters, so predicted bank defaults increase for a majority (63\%) of borrowers in the market. The lower panel shows a similar distribution of exposure using the contemporaneous training set.

We split borrowers into three groups according to the change in predicted default: the 'positive-exposure market', defined as individuals for whom default predictions rise by at least $15 \%$ following deletion, the 'negative-exposure market,' defined as individuals for whom default predictions fall by at least $15 \%$, and the 'zero group,' defined as individuals for whom default predictions change by less than $15 \%$ in either direction. Our findings are robust to changing this threshold value. ${ }^{13}$ When computing exposure we winsorize values in the bottom $5 \%$ of the predicted distributions of default with and without registry data to avoid classifying very small differences in predicted default levels as very large log differences. Our findings are not affected by modifying the winsorization threshold slightly.

Table 3 describes how observable attributes of borrowers vary by exposure. Most

\footnotetext{
${ }^{13}$ We have estimated alternate specifications that vary the threshold between $5 \%$ and $25 \%$; results available upon request.
} 
borrowers are exposed to increases in predicted default from deletion: 53\% of observations fall into the positive-exposure category, compared to $32 \%$ in the zero-change group and $16 \%$ in the negative-exposure group. Almost all borrowers in the negativeexposure group have bank defaults, while almost no borrowers in the positive-exposure group do.

Though the individuals in the positive-exposure group are more likely to come from high-SES backgrounds and have mortgages, the borrowers whose default predictions rise most following deletion are those who resemble negative-exposure borrowers along these dimensions. Figure 7 plots binned means of indicators for holding some mortgage debt at baseline (left panel) and coming from a high-SES background (right panel). Both graphs have upside-down V shapes. About $20 \%$ of borrowers in both the top and bottom deciles of the exposure distribution hold mortgage debt, compared to a maximum of about $30 \%$ for borrowers with modest positive exposure. Similarly, about $25 \%$ of borrowers in the top and bottom deciles of the exposure distribution come from high-SES backgrounds, compared to a maximum of over $60 \%$ for individuals with exposed to slight increases in default predictions. Intuitively, the borrowers who benefit most from the policy are those who are difficult to distinguish from non-defaulters without access to the deleted information. In contrast, borrowers who are relatively unaffected by the policy are those for whom more accurate information about defaults is available outside of the deleted registry.

\subsubsection{Effects of deletion by exposure to changes in predicted bank default}

We isolate the effects of changes in lenders' beliefs about future bank default on borrowing outcomes using a difference-in-differences approach. Intuitively, we compare changes in borrowing outcomes before and after deletion for individuals exposed to increases (and decreases) in beliefs about future bank default to those for individuals with near-zero exposure. We construct cohorts of borrowers at six month intervals leading up to the policy change, including the month of the policy change itself. We then compare the effects of exposure to changes in bank default expectations in the treated cohort to the effects of exposure in pre-treatment placebo cohorts. A crucial assumption we make is that banks' credit supply decisions are correlated with expected default. Although this measure of costs- defaults-is not comprehensive, it is likely to be correlated with banks' supply decisions and ex ante profits. For example, Dobbie et al. (2018) show that banks focus more on default than other measures of costs due to agency concerns with loan officers. 
Consider a sample of individuals who are either not exposed to changes in lender beliefs to deletion, or who are exposed to increases (decreases) in predicted bank default. Within this sample, we estimate specifications of the form:

$$
Y_{i c}=\gamma_{c}+\tau_{c} D_{i c}+X_{i c} \Psi_{c}+e_{i c}
$$

$Y_{i c}$ is borrowing for individual $i$ in cohort $c, \gamma_{c}$ are cohort fixed effects, and $X_{i c}$ are a set of individual covariates that include age, gender, and lagged borrowing and default outcomes. $D_{i c}$ is an indicator equal to one if an individual is in the group exposed to increased (decreased) predicted bank default.

The coefficients of interest are the $\tau_{c}$, which capture cohort-specific estimates of the effects of exposure to increases in bank default predictions on borrowing. We normalize $\tau_{c}$ to be zero in the cohort immediateley prior to deletion. If deletion reduces borrowing for exposed individuals, we expect $\tau_{c}$ to be flat in the cohorts leading up to treatment, and then to become negative in the deletion cohort. We measure exposure using random forest predictions trained in the December 2009 pre-period, and as stated above, we define the zero-exposure group to be the set of individuals for whom $\left|E_{i c}\right|<0.15$.

This type of specification can recover the total effect of deletion on borrowing under two assumptions. The first is the standard difference-in-differences assumption that borrowing in the non-zero exposure groups follows parallel trends to the zero exposure group. We can evaluate this assumption by looking at pre-trends in the $\tau_{c}$. The second assumption is that deletion of credit bureau defaults does not affect borrowing outcomes for individuals in the zero-exposure group. If the deletion raised (lowered) borrowing in the zero-exposure group, our estimates will understate (overstate) the gains in borrowing attributable to deletion. We revisit this assumption below using a supplementary difference-in-differences approach. We also use the difference-in-differences specifications to estimate the effects of deletion on realized default.

Statistical inference is not straightforward in this setting. We would like to allow for correlation in error terms within the categories that banks use to estimate default, but we do not observe what these categories are. We use an auxiliary machine learning step to identify interactions of covariates within which individuals have similar expected default (i.e., each of these interactions identifies smaller "markets" where borrowers look similar to lenders). We then cluster standard errors in our regressions within groups defined by these interactions. There are 330 such groups in the full sample. Inference is robust to changes in the coarseness of these groupings.

Figure 8 and Table 4 report estimates of equation 1 . These estimates recover effects 
for borrowers exposed to positive and negative shocks to bank default predictions relative to the group where bank default predictions do not change following deletion. Bank' expectations for both groups are flat in the year leading up to deletion. At the time of deletion, log bank default predictions rise by 0.22 in the positive exposure group and fall by 0.29 in the negative exposure group. Pre-trends in borrowing are also flat for both groups in the year leading up to deletion. Following deletion, borrowing falls by $\$ 14,000$ CLP in the positive exposure group, equal to $6.4 \%$ of pre-period mean for that group. Borrowing rises by $\$ 17,000$ CLP for the negative exposure group, equal to $11.8 \%$ of the pre-deletion mean. The implied elasticity of borrowing with respect to changes in default predictions is $-0.29(-0.40)$ in the positive (negative) exposure group.

These estimates indicate that the net effect of deletion was to reduce borrowing. The group exposed to increases in predicted default consists of 2.1 million individuals. At an average loss of $\$ 14,000$ CLP per person, the total loss is just under $\$ 30$ billion CLP, or $\$ 60$ million USD at an exchange rate of 500 CLP per dollar. The group exposed to decreases in predicted default consists of 608,000 individuals, with an average gain of $\$ 17,000$ CLP per person and a total gain of $\$ 10$ billion CLP or $\$ 20$ million USD. The net effect of deletion across the two markets was thus to reduce borrowing by $\$ 20$ billion CLP, or $3.5 \%$ of the total borrowing across the two groups. ${ }^{14}$ To the extent the goal of deletion policy was to increase access to credit, it appears to have been counterproductive.

The effects of deletion are largest for the low-SES borrowers who are most exposed to changes in predicted costs. Table 5 repeats the analysis from Table 4, subsetting by whether borrowers have a mortgage at baseline, and by our predicted measure of socioeconomic status. Individuals without mortgages and lower-SES individuals are more responsive to changes in lenders' expectations, and experience larger percentage changes in borrowing. For individuals without mortages, exposure to increased (decreased) expected default lowers (raises) borrowing by $7.1 \%(12.3 \%)$ of baseline values. For individuals with mortgages, the percent decline (rise) in quantity borrowed is $2.8 \%$ $(9.7 \%)$. For low-SES individuals, the percent decrease (increase) in quantity borrowed is $9.2 \%(12.4 \%)$ compared to $6.1 \%(7.7 \%)$ for high-SES individuals.

\subsubsection{Comparison to no-deletion group}

We test the assumption of no effect on the zero-exposure group using two strategies. First, we exploit the 2.5 million pesos policy cutoff in a difference-in-differences test. We

\footnotetext{
${ }^{14}$ This is consistent with Kulkarni, Truffa and Iberti (2018) who show evidence of a drop in aggregate new credit in Chile in after the deletion as part of their analysis of a different credit market policy.
} 
test for differential changes in new consumer borrowing for individuals whose credit bureau defaults add up to less than 2.5 million pesos, who were exposed to the policy change, relative to individuals whose defaults add up to more (or equal) than 2.5 million pesos, who were not exposed to the policy change. To control non-parametrically for differences in new borrowing along the distribution of amount in default, we restrict our analysis to a bandwidth of 250 thousand pesos around the policy cutoff. ${ }^{15} \mathrm{We}$ compute this change in new borrowing for the three cohorts prior to the policy change (June 2010, December 2010, and June 2011) and the cohort exposed to the policy change (December 2011).

For each cohort we divide the sample in two groups defined by our machine learning predictions: negative-exposure individuals, for whom predicted default drops by more than $15 \%$, and the zero-exposure group. There are no individuals exposed to an increase in predicted default in this sample of individuals, as these are all individuals who already are in default at relatively high amounts. ${ }^{16}$ We run the following specification differentially for the two groups:

$$
Y_{i c}=\gamma_{c}+\tau_{c} \times 1\left[\text { Default }_{i c}<2,500,000\right]+e_{i c}
$$

where, again, $Y_{i c}$ is borrowing for individual $i$ in cohort $c$. The $\gamma_{c}$ are cohort fixed effects. $1\left[\right.$ Default $\left._{i c}<2,500,000\right]$ is an indicator equal to one if total credit bureau defaults for individual $i$ in cohort $c$ add up to less than 2.5 million pesos. The $\tau_{c}$ are the effects of interest, capturing how borrowing changes after registry deletion in 2011 for individuals whose amount in default is less than the policy cutoff of 2.5 million pesos.

This test recovers the causal effect of the policy change for the zero-exposure and negative-exposure groups under the assumption of no differential trends for individuals above and below the cutoff, which we examine visually with pre-trends. If our assumption that deletion does not affect borrowing for the zero-exposure group is correct, we should see no change in outcomes for this group following deletion. An increase in borrowing for the negative-exposure group would help make the zero-group test more compelling by showing that the deletion policy and our measures of exposure to that policy are good predictors of outcomes not just overall but within the subgroup

\footnotetext{
${ }^{15}$ Our findings are robust to widening or narrowing this bandwidth, although standard errors grow due to small sample sizes at very narrow bandwidths. We obtain near-identical findings in RD-DD specifications that allow for separate linear trends in default amount above and below the cutoff value in each cohort relative to policy change. These results are available upon request.

${ }^{16}$ To compute predicted default for the above-threshold group under the information deletion policy we apply the predicted values from the machine learning exercise described above based on observable covariates $X_{i c}$.
} 
of relatively large defaulters.

We present the findings in Figure 9. The coefficients of interest of equation (2) for the zero-group are indistinguishable from zero before the policy change, indicating no pre-trends, and indistinguishable from zero after the policy change, which is consistent with the identification assumption for our main analysis. The graph also shows a large increase in borrowing for high-default individuals, exposed to decreases in predicted default, whose defaults are less than the $2.5 \mathrm{~mm}$ pesos cutoff after the policy change. This rules out that the absence of an effect for the zero-group after the policy change is driven by a lack of power to identify any effects of the policy change among highdefault individuals and is consistent with the main findings in this paper.

\subsubsection{Cross-time comparison}

Second, we implement a difference-in-differences specification that exploits variation within borrower cohorts by time relative to deletion. Let $t$ index six-month periods relative to the period beginning in February of calendar year $c$. Within the zero exposure groups, we estimate equations of the form:

$$
Y_{i c t}=\gamma_{c}+\theta_{t}+\tau_{t} \times 1\left[c=c_{T}\right]+e_{i c t}
$$

where $Y_{i c t}$ is borrowing for individual $i$ in cohort $c$ at time relative to deletion $t$. The $\gamma_{c}$ and $\theta_{t}$ are cohort and event-time fixed effects, respectively. $1\left[c=C_{T}\right]$ is an indicator equal to one if $c$ is the treated cohort $c_{0}$. Here, the $\tau_{t}$ are the effects of interest, capturing how borrowing changes after registry deletion in 2011 relative to changes at the same time of year in previous years.

This specification will capture unbiased estimates of the effect of deletion of credit bureau defaults on borrowing for the zero-exposure group if time-of-year effects are the same in the 2011 and earlier borrowing cohorts. It differs from the main approach in section 3.2 in the requirements for unbiased estimation. In particular, our main approach differences out time-varying shocks that affect all borrowers by measuring outcomes relative to the zero-exposure group. This supplementary specification requires the strong asssumption that seasonal effects be constant across years.

We present our findings in Figure 10. We follow borrowing outcomes for a year before and after deletion, divided into six month windows. Borrowing grows more rapidly in the pre-deletion period for the 2011 cohort than it did in earlier cohorts, suggesting that seasonal effects may differ from year-to-year. Following deletion, the trend reverses, and borrowing falls for the cohort treated with information deletion relative 
to the control cohort. That is, following deletion borrowing falls relative to the predeletion baseline and even more relative to the pre-deletion trend for the zero-exposure group. Though the presence of pre-deletion trends argues for caution in interpretation, these findings are hard to reconcile with a claim that information deletion raised borrowing in the zero exposure group. It follows that our main estimates of the effects of deletion underestimate the decline in borrowing from the deletion policy, if anything.

\subsection{Additional evidence: borrowing from non-banks}

The effects of deletion on aggregate borrowing could be reduced if individuals subject to higher prices for bank credit shift towards non-bank borrowing. The largest nonbank lenders in Chile are department stores that issue credit cards. We explore how borrowing changed at these institutions using publicly-available aggregate data on retail credit card lending provided by SBIF. Appendix Figures A1, A2, and A3 show no distinct breaks in the total stock of retail credit cards, the number of retail credit cards used, or the amount transacted at the time of deletion.

These findings are consistent with the hypothesis that deletion reduced aggregate borrowing. Deletion effects in the retailer-issued credit card market may be smaller than in the consumer bank lending market because low-risk individuals are very unlikely to borrow in that market both before and after deletion. Median interest rates for retailer credit card lending are 75\% higher than for non credit-card consumer bank lending just before deletion ( $45 \%$ vs. $26 \%$ in November 2011 ) and remain higher following deletion (e.g. $45 \%$ vs. $31 \%$ in February 2012). ${ }^{17}$ That few individuals subsitute from consumer credit to credit card borrowing is consistent with the observation that prices remained lower in the consumer credit market following the deletion.

In fact, the deletion may have induced a larger effect on non-defaulters among nonbanks than banks. While banks continued to observe bank defaults (at all other banks) following deletion, the deleted credit bureau information was the only default information available to non-bank lenders. Because there is no micro-level data for non-bank lenders, we cannot directly calculate how exposure to the policy affects non-bank lending, but our results for bank lending suggest there may be aggregate losses there too. In section 5 below we use our empirical strategy to evaluate the effects on bank lending of a counterfactual policy change that would delete all bank defaults, which is similar to the informational change for non-banks after the policy change.

\footnotetext{
${ }^{17}$ Credit cards are subject to a rate cap that was likely binding for retailer cards during this period.
} 


\section{The effects of information deletion on total surplus}

The deletion policy reduced overall consumer borrowing, with declines for borrowers exposed to increases in predicted default more than offseting gains for borrowers exposed to decreases in predicted default. However, the policy may still have raised total surplus if it transferred borrowing from individuals who value credit less relative to costs to individuals who value it more. To explore the effects of pooling on surplus, we present a simple framework adapted from Einav, Finkelstein and Cullen (2010) and use our difference-in-difference estimates as inputs to the framework. Our focus is on understanding how deletion affects surplus and borrowing outcomes through adverse selection, not moral hazard. This is consistent with the empirical application we study here, a one-time deletion based on characteristics that were predetermined at the time of policy announcement.

Consider a consumer credit market where lenders set interest rates on the basis of observable borrower characteristics but borrowers have private information on the cost of lending. Assume for simplicity that the lending market is competitive, so that in equilibrium rates are equal to average costs. As in Einav et al. (2010), lenders set rates and quantities are endogenously determined.

Individual borrowers are denoted by $i$. Lenders partition markets using two types of borrower characteristics. The first type, $X_{i}$, is always observable to lenders. For the rest of this section, we think of the analysis as taking place within subgroups of borrowers defined by $X_{i}=x$. This captures the fact that in general lenders offer different prices to observably different borrowers. The second type, $Z_{i} \in\{0,1\}$, is a variable that will be deleted from the lender's information set, e.g., by the policy change. We model $Z_{i}=1$ as being a default flag that predicts higher costs. To guarantee unique equilibria, we assume that the (inverse) demand curve crosses the marginal cost curve from above exactly once in both the high- and low-cost markets. For analytic tractability, we further assume that the demand and cost curves are linear.

Figure 11 summarizes the results of this analysis, with technical details available in Online Appendix C. The left panel describes the high-cost market $\left(Z_{i}=1\right)$ and the right panel describes the low-cost market $\left(Z_{i}=0\right)$. Because of adverse selection, marginal cost curves are downward sloping and equilibrium price and quantity in each market are determined by the intersection of market-specific average cost and demand curves. These are labeled, respectively, $A C_{z_{j}}$ and $D_{z_{j}}$ in the graph. $q_{j}^{e}$ is the pre-deletion equilibrium quantity borrowed in market $j$.

The surplus-maximizing quantity and price in each market are in turn given by 
the intersection of market-specific demand and marginal cost curves, the latter labeled $M C_{z_{j}}$. Below we show evidence consistent with adverse selection in both markets, and therefore of surplus losses due to asymmetric information in both markets. In Figure 11, these losses are given by the areas of triangle $\mathrm{A}$ in the high cost market and $\mathrm{B}$ in the low-cost market.

After deletion, lenders no longer observe $Z_{i}$ and must set one price for both $Z_{i}=0$ and $Z_{i}=1$. The demand curve in the pooled market is given by the sum of marketspecific demand curves, while the pooled average cost curve is a quantity-weighted sum of the market-specific average cost curves. Equilibrium prices and quantities in the pooled market are determined by the intersection of the pooled $A C$ curve and the pooled demand curve. We denote the pooled equilibrium price $A C^{p}$ and mark it with a horizontal line in Figure 11. The quantity borrowed in each market is given by the intersection of the market-specific demand curve and $A C^{p}$. We focus on the empirically relevant case where borrowing rises (and prices fall) in the high-cost market and the reverse takes place in the low-cost market, with quantities in market $Z_{i}=j$ labeled as $q_{j}^{p}$ in the graph.

Changes in total surplus from pooling are determined by the relationship between the group-specific demand and cost curves and the pooled average costs. For individuals with $Z_{i}=0$ at baseline, rising rates due to pooling increase surplus losses due to underprovision of credit. These additional losses are denoted by triangle $\mathrm{D}$ in the right panel of Figure 11, the low-cost market. For individuals with $Z_{i}=1$, the effects of pooling on surplus are ambiguous. If $A C^{p}$ is above the point where the marginal cost and demand curves cross, the effects of the policy on surplus within this market are unambiguously positive, as pooling reduces the underprovision of credit due to adverse selection. If $A C^{p}$ is below the efficient price, then the effects are unclear. Losses from overprovision in the pooled market may outweigh losses from underprovision in the segregated market. Figure 11 illustrates the latter case, with surplus losses from overprovision equal to the area of triangle $C$ in the left panel. As we discuss in more detail in Online Appendix C, we can obtain analytic solutions for these quantities given observations of a) the unpooled quantities and costs, and b) slopes of the demand and cost curves in each market.

In general, the slopes of the demand and cost curves can be estimated using any exogenous shock to rates in each market. To tie our welfare analysis to the policy evaluation, we exploit shocks to lenders' predictions about borrowers' probability of default due to information deletion, and use the results from the difference in differences analysis to estimate elasticities. We assume that the expected probability of default ap- 
proximates bank's expectations of the cost of lending to an individual. Thus, under a policy of average cost pricing these shocks translate directly into rates. We map the high-cost and low-cost markets in the framework to the markets that face a reduction and an increase in predicted defaults in our empirical implementation, i.e., the markets with negative and positive exposure, respectively.

We estimate the slope of the demand curve in each market using results from Table 4. To estimate the slope of the average cost curve, we use our diff-in-diffs procedure to estimate the effect of deletion on realized costs in the high- and low-cost markets. We focus on a simple measure of realized costs: an indicator variable equal to one if a borrower adds to his default balance in the six month period following each registry snapshot. This is consistent with our assumption that defaults approximate lender costs. We estimate realized cost effects within the sample of individuals who have new borrowing over the six-month period. We make this restriction because the goal of the exercise is to recover cost curve slopes for market participants.

Table 6 reports the effects of deletion on realized average costs in the low-cost (columns 1-5) and high-cost markets (columns 6-10), in the full sample and split by mortgage and SES categories. At baseline, the average cost for borrowers in the low-cost market is 0.04 , and the average cost in the high-cost market is 0.10 , which verifies that registry defaults are correlated with future bank defaults. ${ }^{18}$ Deletion slightly raises average costs for borrowers in the low-cost group and lowers average costs in the high-cost group. Because quantities fall in the low-cost group and rise in the high-cost group, the signs of these point estimates are consistent with downward-sloping average cost curves, and thus with adverse selection, in both markets. However, in neither case can we reject an effect of zero at conventional levels of significance. These findings suggest that adverse selection is not large conditional on the information available to borrowers before deletion takes effect, and that surplus losses due to asymmetric information may be limited prior to deletion.

\subsection{Benchmark estimates}

We first consider the following thought experiment: for a market at the average value of pooled average costs, which we denote $A C(x)$, what is the effect on consumer surplus

\footnotetext{
${ }^{18}$ In Appendix Table A2 we repeat the analysis from Table 6 using one-year-ahead bank default rather than six-month-ahead bank default to proxy for costs. Estimated effects of deletion on borrowing levels are close to unchanged relative to the benchmark analysis. We prefer our benchmark estimates because using one-year-ahead default measures means that some defaults attributed to loans originated in the pre-deletion period occur following deletion, which does not occur when we use the six-month-ahead measure.
} 
of moving from an equilibrium where lenders can condition prices on the credit bureau default flag $z$ to one where they cannot? The mean value of $A C(x)$ is 0.050 . Conditional on $\log A C(x)$, costs are $43 \%$ lower for the low-cost group, exposed to increase in predicted default, and $36 \%$ higher for the high cost group, exposed to decreases in predicted default, for level values of separate-market average costs $A C(x, z)$ of 0.029 and 0.069 in the low- and high-cost markets respectively.

Panels A and B of Figure 12 show the demand, average cost, and marginal cost curves in the low-cost and high-cost markets, respectively. Demand curves reflect average quantity borrowed by an individual in each market. The pre-deletion equilibrium in each market is determined by the intersection of the demand and average cost curves. Equilibrium $(q, p)$ pairs are $(113,0.069)$ and $(252,0.029)$ in the high- and low-cost markets, respectively. The average quantity borrowed across both markets is 220 and the average rate is 0.033 . Average cost curves slope down in both markets, leading to underprovision relative to the efficient quantity. Demand is less elastic in the high-cost market than the low-cost market. This means that for some common offer rate $R$ in both markets, the share of high cost types in market rises with $R$. In our linear parameterization, the share of high-cost types in the market is equal to one for $R>0.14$.

Panel $C$ of Figure 12 shows the pooled demand, average cost, and marginal cost curves. The demand curve is piecewise linear, with the slope becoming flatter when the low-cost types enter the market at lower prices. The pooled average cost curve is the quantity-weighted average of the average cost curves in the low- and high-cost markets. The marginal cost curve follows the high-cost curve at very high prices, then shifts rapidly downward as the low-cost types enter the market. Equilibrium rate and average quantity in the pooled market are given by the intersection of the pooled demand curve and the pooled average cost curve, with $(q, R)=(215,0.035)$. Quantity borrowed declines on average, and rates rise. The effects of pooling on surplus differ in the high- and low-cost markets. In the low-cost market, pooling exacerbates welfare losses from underprovision. In the high-cost market, the pooled price is below the intersection of the demand and marginal cost curves, so welfare losses in the pooling equilibrium come from overprovision.

Table 7 summarizes the quantitative implications of this analysis. In the low-cost market, the equilibrium rate rises from 0.029 before deletion to 0.035 afterward, while average costs do not meaningfully change. Quantity borrowed declines by an average of $\$ 13,000$ CLP per person, or a total of $\$ 26.4$ billion CLP. The surplus loss relative to the efficient quantity rises by $106 \%$ of the baseline value. In contrast, rates in the high-cost market drop from 0.069 to 0.035 , and borrowing rises by $\$ 28,000$ CLP per person, or $\$ 17$ 
billion CLP in aggregate. Welfare losses in this market decline by 73\%. Aggregating across markets, borrowing falls by $\$ 9$ billion CLP, and surplus losses rise by an amount equal to $66 \%$ relative to baseline. ${ }^{19}$

\subsection{Markups over average cost}

Our analysis of the effects of deletion on surplus thus far assumes that lenders do not mark up rates over costs. If borrowers face imperfect competition and are able to mark up prices relative to our cost measures, our analysis will systematically underestimate how much consumers value borrowing. ${ }^{20}$ Further, if borrowers in the high- and lowcost markets face different markups at baseline, we will mismeasure their relative valuations. To explore how different assumptions about markups in the high- and low-cost markets affect our analysis, we augment the model by adding markups relative to average costs. We consider the effects of raising markups overall, and of raising markups in the pre-deletion high-cost market relative to the low-cost market.

Recall that in benchmark case, the pre-deletion equilibrium quantity and rate in each market were determined by the intersection of the market-specific demand and average cost curves. We now add a market-specific markup term $m_{j}$ for rates relative to average costs, so that for each market $j, R_{j}^{e}=\left(1+m_{j}\right) \times A C_{j}^{e}$. In the pooled market we allow a markup of value $m_{p}$ over average costs. Within this framework we conduct the following exercise. We fix the low-cost market markup $m_{0}$ at a value $\mu_{0}$, and set the high-cost market markup $m_{1}$ to $m_{1}=\mu_{0} \times\left(1+\mu_{1}\right)$. We cycle through combinations of $\mu_{0}$ and $\mu_{1}$, in each case setting $m_{p}$ to the quantity-weighted average markup in the pre-deletion period so that deletion does not affect the average markup in the market.

Figure 13 and Appendix Table A1 show the percentage changes in surplus loss relative to baseline value in both markets combined for different combinations of $\mu_{0}$ and $\mu_{1}$. Surplus losses persist as we raise markups in both markets equally. As markups rise, both losses in the low-cost market and gains in the high-cost market rise in absolute value. This makes sense: higher markups mean that the consumers in both markets place a higher value on borrowing, leading to higher welfare stakes. Net losses rise in levels but fall in percentage terms due to a larger denominator.

Augmenting the markup in the high-cost market relative to the low-cost baseline tends to reduce the surplus losses from pooling. Again, this makes sense. Higher

\footnotetext{
${ }^{19}$ Appendix Table A3 summarizes the analysis using one-year ahead default as a proxy for cost, which lead to larger estimates of surplues losses in the low-cost market. In aggregate, surplus losses are larger in levels but smaller in percentage terms (42\%) due to larger estimates of welfare losses at baseline.

${ }^{20}$ Ausubel (1991) shows evidence of lack of competition in the US credit card market.
} 
markups for high-cost borrowers mean that those individuals value borrowing more. At baseline markup levels up to $25 \%$, surplus losses persist for additional high-cost markups of up to $100 \%$. The effects of pooling on total surplus become zero or modestly positive in percentage term when markups are very high overall, and there are large additional markups in the high-cost market. According to our analysis, the deletion policy breaks even in surplus terms when, a) overall markups are large, and b) markups in the high cost market are larger relative to the low cost market. For example, we find that pooling breaks even in surplus terms when the low-cost markup is $50 \%$ and the additional high-cost markup is $100 \%$, and may even reduce surplus losses relative to the efficient outcome by $11 \%$ when the low-cost market markup is $200 \%$ and the high-cost market markup is an additional 100\%.

The assumption underlying this analysis- that pooling does not affect the average markup- may be violated if deletion affects market power (Mahoney and Weyl (2017)). However, the data show that rates and defaults increase proportionally following deletion, which suggests our assumption may hold. Figure 2 shows that after the deletion the median consumer credit rate increases by 5.3 percentage points from a base of $26 \%$, a $20 \%$ increase. The increase in the median rate is similar to the estimated $22 \%$ increase in predicted default for the low-cost market (the median borrower is not in default, i.e. low cost), shown in Table 4, column 3.

We also note that deletion may have dynamic welfare effects (Handel et al. (2015), Clifford and Shoag (2016), Bartik and Nelson (2016), Cortes et al. (2016), and Kovbasyuk and Spagnolo (2018)) or welfare effects outside of the credit markets (Bos et al. 2018, Herkenhoff et al. 2016, Dobbie et al. 2016). One can view our findings as measures of the costs of providing these benefits.

\section{Evaluation of counterfactual deletion policies}

The methodology used above to study the effects of the large-scale deletion of credit bureau defaults provides a framework through which policymakers can predict the distributional and aggregate effects of changes in any type of credit information. In this section we apply this methodology to two hypothetical changes in the credit information available to lenders. The first is a deletion of information about gender. The idea of eliminating the use of demographic information has parallels in US anti-discrimation laws as applied to credit markets (Munnell et al. 1996, Blanchflower et al. 2003, Pope and Sydnor 2011). The second is deletion of banks' internal and external default records across all banks in addition to the credit bureau defaults. This is a more radical version 
of the original policy.

In each case, we can simulate the effects of counterfactual policies using the following procedure. First, we compute each individual's (log) exposure to the policy by estimating predicted costs with and without the deleted information. We then take our estimates of exposure to cost changes, and scale them by an estimated elasticity of borrowing with respect to costs. For example, we can use the elasticity estimates from Table 4.

We present the analysis in Table 8, which mimics Table 3 for our baseline analysis. For each of the two counterfactual policies, we split the sample into individuals whose costs increase by $15 \%$ or more, individuals whose costs decrease by $15 \%$ or more, and the zero change group, which groups everyone else. This follows the procedure from our analysis of the observed deletion policy.

The top panel presents the first counterfactual policy, deletion of the gender indicator. Three things emerge from the analysis. First, most individuals ( $87 \%$ of the sample) belong to the zero change group. This is because the distribution of changes in costs is much tighter than in our baseline analysis, as is evident in the histogram of exposures shown in Figure 14. Second, as expected, gender is a strong predictor of cost changes: $98 \%$ of individuals exposed to cost increases are female, while females only represent $16 \%$ of those exposed to cost decreases. Thus, women would experience average increases in predicted costs following a deletion of the gender flag. Third, individuals whose costs increase or decrease have no registry defaults, and little variation in socioeconomic status. These variables have little explanatory power for changes in banks' expected costs following deletion of the gender flag, which is consistent with the fact that costs do not change much when gender is deleted.

The bottom panel shows the second counterfactual policy, deletion of banks' internal default records in addition to consolidate default. Unsurprisingly, the more radical deletion option leads to larger changes in predicted costs than the actual deletion policy, as only $13 \%$ of the distribution is concentrated in the zero change group. This point is also shown in Figure 14. This suggests that the measure of defaults is highly predictive of future bank costs. Second, gender is uncorrelated with changes in costs following deletion of bank defaults, while bank defaults are, unsurprisingly, highly correlated with changes in predicted costs. Finally, socio-economic status is also correlated with changes in predicted costs: individuals exposed to reductions in costs are about 20 percent more likely to belong to a low socio-economic status group than those exposed to increases.

If one is willing to assume that elasticities of borrowing with respect to changes in 
average costs are the same as what we observe in the analysis of the observed deletion policy, we can go beyond the analysis of changes in the predicted cost distribution and predict the effects of these counterfactual deletion policies on borrowing. For example, if we take an estimated elasticity of -0.29 from Table 3 and multiply by the mean measures of exposure to the gender deletion in each group, we get that groups exposed to increases in costs see a 7 percent decline in new borrowing, a decline of $\$ 4,400$ CLP per borrower, while groups exposed to decreases in costs see a 7.3 percent increase in new borrowing, an increase of \$5,600 CLP per borrower. Multiplying each effect by the number of individuals in each group implies a near-zero change in aggregate new borrowing. The counterfactual deletion of banks' default records leads to a $18 \%$ drop in lending for individuals exposed to increases in costs and a $25 \%$ increase in lending for individuals exposed to decreases in costs. These effects aggregate to a drop in lending of $\$ 42$ billion CLP over a six month period, roughly twice the size of the $\$ 20$ billion CLP net effect of the observed deletion policy.

\section{Conclusion}

This paper explores the equilibrium effects of information asymmetries on credit markets in the context of a large-scale policy change that forced credit bureaus to stop reporting past defaults for the majority of defaulters in the Chilean consumer credit market.

To estimate the causal effects of deletion on consumer credit borrowing, we implement a difference-in-differences test that compares the evolution of borrowing for individuals whose predicted bank default increases or decreases as a consequence of the deletion of information relative to individuals whose predicted bank default does not change. We compute predictions of default using using a machine learning approach. Our core empirical finding is that losses from information deletion are regressive and outweigh gains in this setting: consumer borrowing falls by $3.5 \%$ after the policy change, with the largest losses for lower-income individuals with smaller borrowing balances. Using a simple framework, we estimate the effects of the policy change on total surplus under several assumptions of bank pricing policies. There is no evidence that the winners from the policy value borrowing sufficiently more than the losers to offset these losses.

Our findings suggest that although policies that limit information availability in credit markets can raise total surplus, they should be deployed cautiously. Even if deletion lead to increased borrowing for defaulters, it may reduce lending over all. A 
feature of deletion policies is that the biggest losers tend to resemble the biggest winners on all characteristics observable to the lender other than the deleted information, so policies implemented with the goal of helping disadvantaged populations also have greatest risk of negative effects for these populations.

Our findings motivate a simple procedure by which policymakers can predict the distributional consequences of a proposed change in credit information. The procedure is to construct default/cost predictions before and after the change, and identify the individuals with the biggest gains and losses in predicted costs. These estimates can be used alone to classify likely winners and losers, can be paired with estimates of demand elasticities to predict changes in quantity borrowed, or can be combined with estimates of demand and cost elasticities to predict changes in surplus. This approach can also be applied to understanding how existing information-restricting institutions such as sunset provisions affect lending. We leave this exercise for future research. 


\section{References}

Agan, Amanda and Sonja Starr, "Ban the Box, Criminal Records, and Racial Discrimination: A Field Experiment," The Quarterly Journal of Economics, 2017, 133 (1), 191235.

Agarwal, Sumit, Souphala Chomsisengphet, Neale Mahoney, and Johannes Stroebel, “Do Banks Pass Through Credit Expansions to Consumers who Want to Borrow?," Quarterly Journal of Economics, 2018, 133 (1).

Akerlof, George A, "The Market for "Lemons": Quality Uncertainty and the Market Mechanism," The Quarterly Journal of Economics, 1970, 84 (3), 488-500.

Athey, Susan and Guido Imbens, "Recursive Partitioning for Heterogeneous Causal Effects," Proceedings of the National Academy of Sciences, 2016, 113 (27), 7353-7360.

and Stefan Wagner, "Estimation and Inference of Heterogeneous Treatment Effects using Random Forests," Working Paper, 2017.

Ausubel, Lawrence M., "The Failure of Competition in the Credit Card Market," The American Economic Review, 1991, 81 (1), 50-81.

Bartik, Alexander W. and Scott Nelson, "Credit Reports as Resumes: The Incidence of Pre-Employment Credit Screening," Working Paper, 2016.

Bester, Helmut, "Screening vs. Rationing in Credit Markets with Imperfect Information," American Economic Review, 1985, 75 (4), 850-55.

Blanchflower, David G, Phillip B Levine, and David J Zimmerman, “Discrimination in the small-business credit market," The Review of Economics and Statistics, 2003, 85 (4), 930-943.

Bos, Marieke and Leonard I Nakamura, "Should Defaults be Forgotten? Evidence from Variation in Removal of Negative Consumer Credit Information," Technical Report, FRB of Philadelphia Working Paper 2014.

_ Emily Breza, and Andres Liberman, "The Labor Market Effects of Credit Market Information," Review of Financial Studies, 2018, 31 (6), 2005-2037.

Breiman, Leo, “Random Forests," Machine Learning, 2001, 45, 5-32. 
, Jerom Friedman, Charles J. Stone, and R.A. Olshen, Classification and Regression Trees, Chapman and Hall/CRC, 1984.

Brown, M. and C. Zehnder, "Credit Reporting, Relationship Banking, and Loan Repayment," Journal of Money, Credit and Banking, 2007, 39 (8), 1883-1918.

Burlig, Fiona, Christopher Knittel, David Rapson, Mar Reguant, and Catherine Wolfram, "Machine Learning From Schools About Energy Efficiency," NBER Working Paper, 2017, (w23908).

Clifford, Robert and Daniel Shoag, "'No More Credit Score" Employer Credit Check Banks and Signal Substitution," Working Paper, 2016.

Cortes, Kristle, Andrew Glover, and Murat Tasci, "The Unintended Consequences of Employer Credit Check Bans on Labor and Credit Markets," Working Paper, 2016.

Cowan, Kevin and Jose De Gregorio, "Credit Information and Market Performance: The Case of Chile," in Margaret J. Miller, ed., Credit Reporting Systems and the International Economy, Vol. 4, Cambridge, MA: MIT Press, 2003, pp. 163-201.

Dobbie, Will, Andres Liberman, Daniel Paravisini, and Vikram Pathania, "Measuring Bias in Consumer Lending," Working Paper 24953, National Bureau of Economic Research August 2018.

_ , Paul Goldsmith-Pinkham, Neale Mahoney, and Jae Song, "Bad Credit, No Problem? Credit and Labor Market Consequences of Bad Credit Reports," Technical Report 22711, National Bureau of Economic Research 2016.

Einav, Liran, Amy Finkelstein, and Mark R Cullen, "Estimating Welfare in Insurance Markets Using Variation in Prices," The Quarterly Journal of Economics, 2010, 125 (3), 877-921.

and Jonathan Levin, "Economics in the age of big data," Science, 2014, 346 (6210), 1243089.

Elul, Ronel and Piero Gottardi, "Bankruptcy: Is It Enough to Forgive or Must We Also Forget?," American Economic Journal: Microeconomics, November 2015, 7 (4), 294338.

Fuster, Andreas, Paul Goldsmith-Pinkham, Tarun Ramadorai, and Ansgar Walther, "Predictably Unequal? The Effects of Machine Learning on Credit Markets," Technical Report, National Bureau of Economic Research 2017. 
González-Uribe, Juanita and Daniel Osorio, "Information Sharing and Credit Outcomes: Evidence from a Natural Experiment," Technical Report, Working Paper 2014 .

Handel, Ben, Igal Hendel, and Michael D Whinston, "Equilibria in health exchanges: Adverse selection versus reclassification risk," Econometrica, 2015, 83 (4), 12611313.

Herkenhoff, Kyle, Gordon Phillips, and Ethan Cohen-Cole, "The impact of consumer credit access on employment, earnings and entrepreneurship," Technical Report, National Bureau of Economic Research 2016.

Huang, Cheng-Lung, Mu-Chen Chen, and Chieh-Jan Wang, "Credit Scoring with a Data Mining Approach Based on Support Vector Machines," Expert Systems with Applications, 2007, 33 (4), 847-856.

Jaffee, Dwight $\mathbf{M}$ and Thomas Russell, "Imperfect Information, Uncertainty, and Credit Rationing," The Quarterly Journal of Economics, 1976, pp. 651-666.

Khandani, Amir E., Adlar J. Kim, and Andrew W. Lo, "Consumer Credit-Risk Models via Machine-Learning Algorithms," Journal of Banking E Finance, 2010, 34 (4), 27672787.

Kovbasyuk, Sergey and Giancarlo Spagnolo, "Memory and markets," Technical Report, Working Paper 2018.

Kulkarni, Sheisha, Santiago Truffa, and Gonzalo Iberti, "Removing the Fine Print: Standardization, Disclosure, and Consumer Loan Outcomes," Technical Report, Working Paper 2018.

Liberman, Andres, "The Value of a Good Credit Reputation: Evidence from Credit Card Renegotiations," Journal of Financial Economics, 2016, 120 (3), 644-660.

Mahoney, Neale and E Glen Weyl, "Imperfect competition in selection markets," Review of Economics and Statistics, 2017, 99 (4), 637-651.

Miller, Margaret J, Credit reporting systems and the international economy, Mit Press, 2003.

Mullainathan, Sendhil and Jann Spiess, "Machine Learning: An Applied EconometricAapproach," Journal of Economic Perspectives, 2017, 31 (2), 87-106. 
Munnell, Alicia H, Geoffrey MB Tootell, Lynn E Browne, and James McEneaney, "Mortgage lending in Boston: Interpreting HMDA data," The American Economic Review, 1996, pp. 25-53.

Musto, David K, "What Happens when Information Leaves a Market? Evidence from Postbankruptcy Consumers," The Journal of Business, 2004, 77 (4), 725-748.

Pedregosa, F., G. Varoquaux, A. Gramfort, V. Michel, B. Thirion, O. Grisel, M. Blondel, P. Prettenhofer, R. Weiss, V. Dubourg, J. Vanderplas, A. Passos, D. Cournapeau, M. Brucher, M. Perrot, and E. Duchesnay, "Scikit-learn: Machine Learning in Python," Journal of Machine Learning Research, 2011, 12, 2825-2830.

Petersen, Mitchell A and Raghuram G Rajan, "Does Distance Still Matter? The Information Revolution in Small Business Lending," The Journal of Finance, 2002, 57 (6), 2533-2570.

Pope, Devin G and Justin R Sydnor, "What's in a Picture? Evidence of Discrimination from Prosper. com," Journal of Human Resources, 2011, 46 (1), 53-92.

Rothschild, Michael and Joseph E Stiglitz, "Equilibrium in Competitive Insurance Markets: An Essay on the Economics of Imperfect Information," The Quarterly Journal of Economics, 1976, 90 (4), 630-49.

Steinberg, Joseph, "Your privacy is now at risk from search engines- even if the law says otherwise," Forbes, June 2014.

Stiglitz, J.E. and A. Weiss, "Credit Rationing in Markets with Imperfect Information," The American Economic Review, 1981, 71 (3), 393-410.

Varian, Hal, "Causal Inference in Economics and Marketing," Proceedings of the Natural Academy of Sciences, 2016, 113 (27), 7310-7315. 
Figures and Tables

Figure 1: Individuals with positive past defaults over time

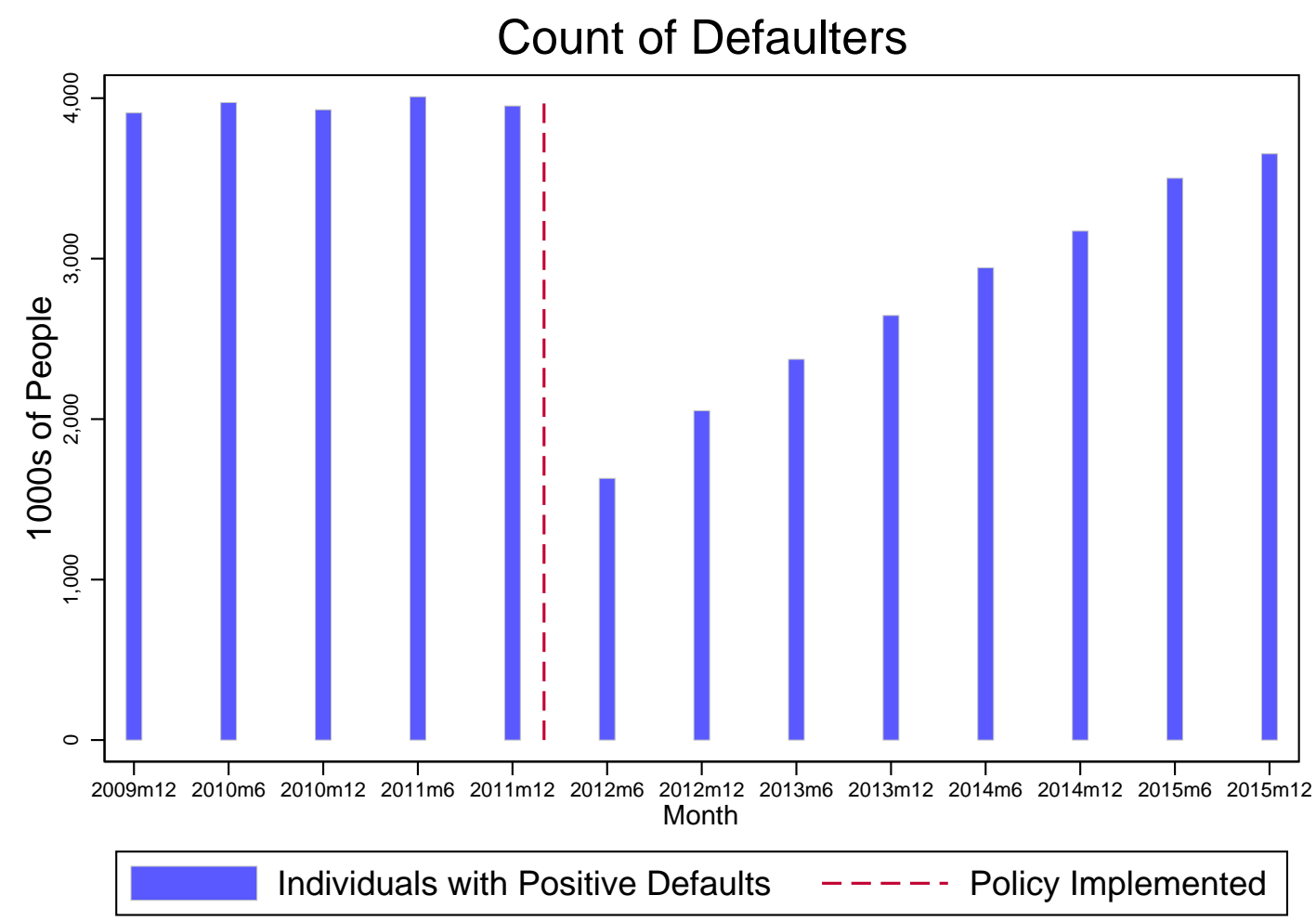

Each bar represents the count of individuals in the credit registry with positive default values at six month intervals. The vertical line represents the implementation of the registry deletion policy. 
Figure 2: Interest rates

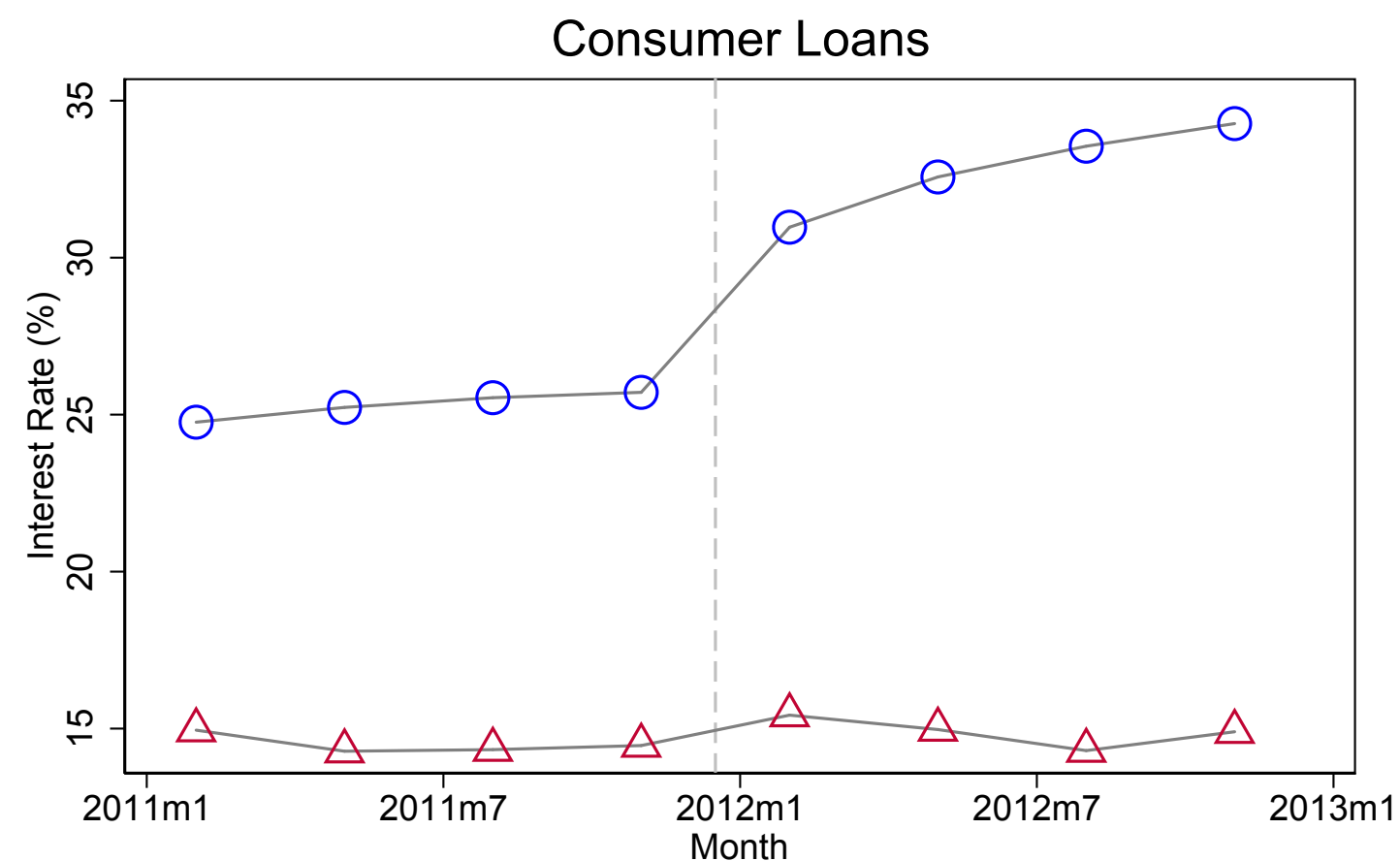

\section{- Small Consumer Loans $\triangle \triangle$ Large Consumer Loans}

End of period median interest rates for small (top) and large (bottom) consumer loans issued by banks, by quarter relative to December 2011-February 2012. Information on rates obtained from website of Superintendencia de Bancos e Instituciones Financieras, www. sbif.cl. 
Figure 3: Histogram of amount in default as of December 2011

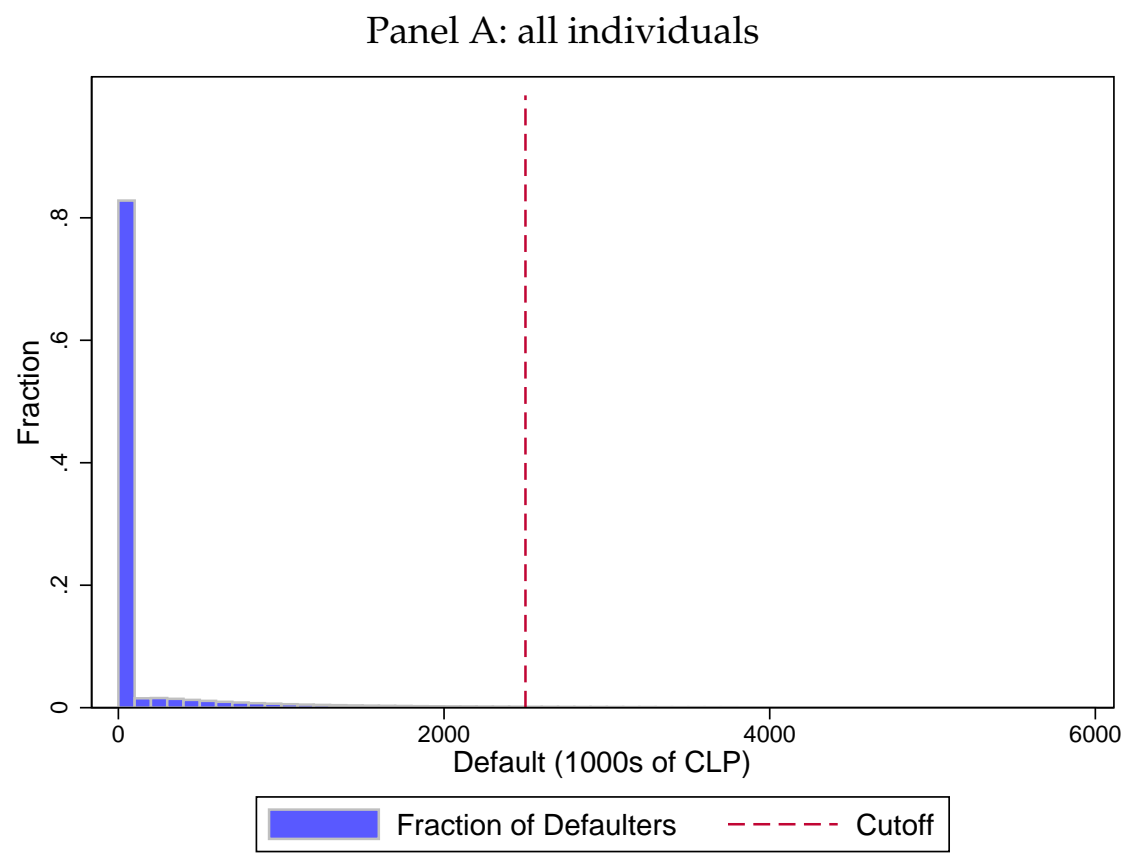

Panel B: conditional on positive default

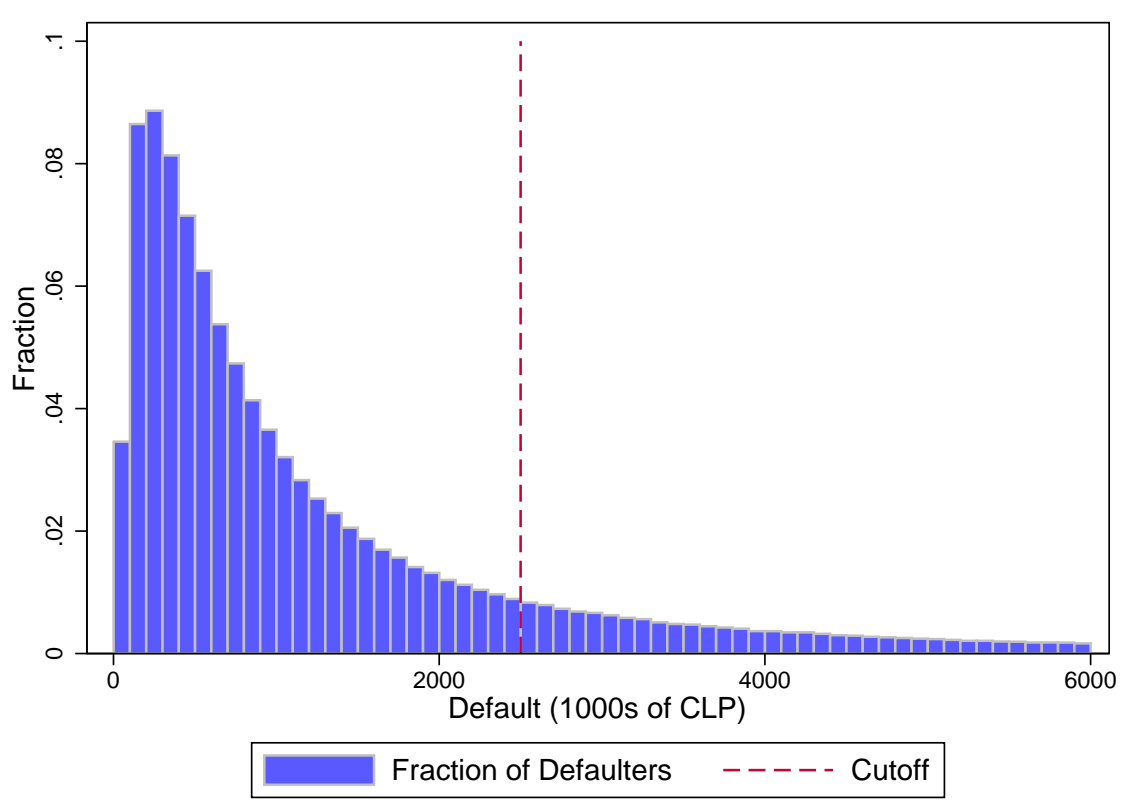

Panel A: Histogram of consolidated defaults as of December 2011, for amounts below \$6 million CLP (approximately $\$ 3,000$ ). Panel B: Histogram of consolidated defaults for individuals with positive defaults only. 
Figure 4: Effects of registry deletion on defaulters relative to non-defaulters
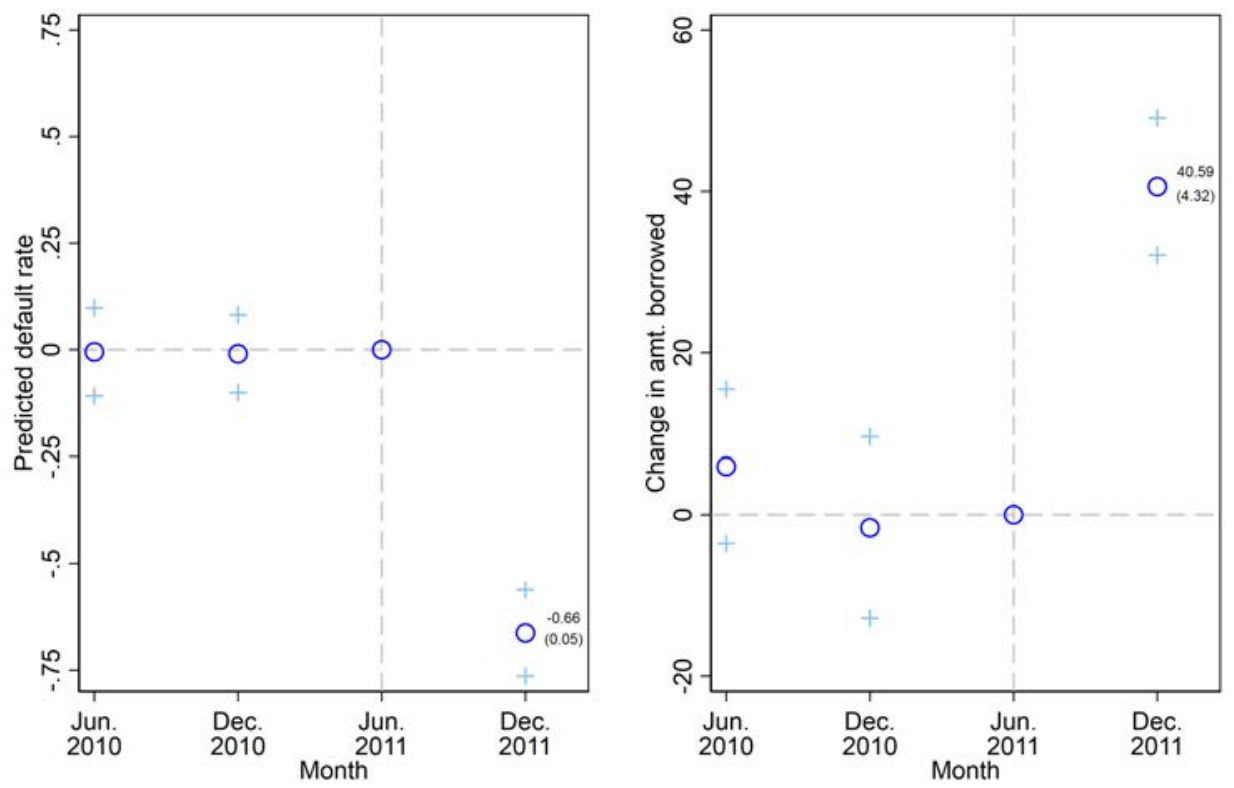

Point Estimate $\quad+95 \% \mathrm{Cl}$

Difference-in-difference estimates and 95\% CIs of the effects of prior default on predicted default rate (left panel) and observed borrowing (right panel) using equation 1. Predicted defaults: $N$ Clusters: 329, $N$ Obs.: 3,228,458, $N$ Individuals: 2,031,005, New Borrowing: $N$ Clusters: 329, $N$ Obs.: 15,513,587, $N$ Individuals: 4,693,948, . Borrowing is measured over six month intervals with $t=0$ in the six month period following deletion in February 2012. Consistent with the implementation of the deletion policy, default status is determined using registry snapshot three months prior to the start of each interval. Standard errors clustered at market level. See text for details. 
Figure 5: Predictions with and without registry data

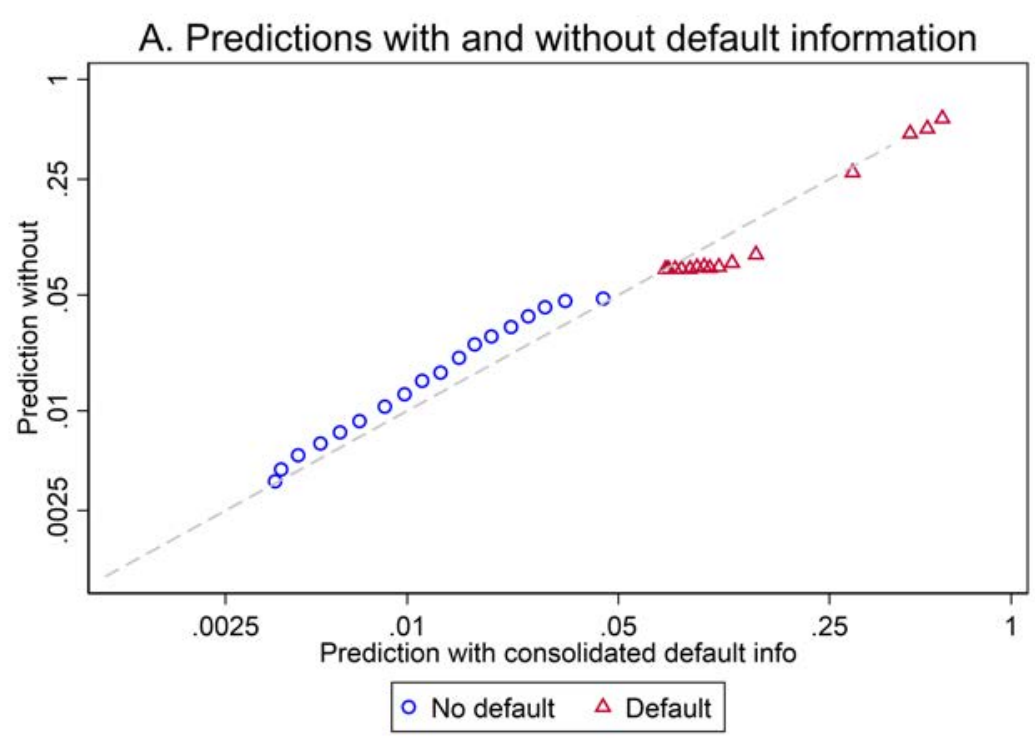

\title{
B. Observed defaults by predicted value
}
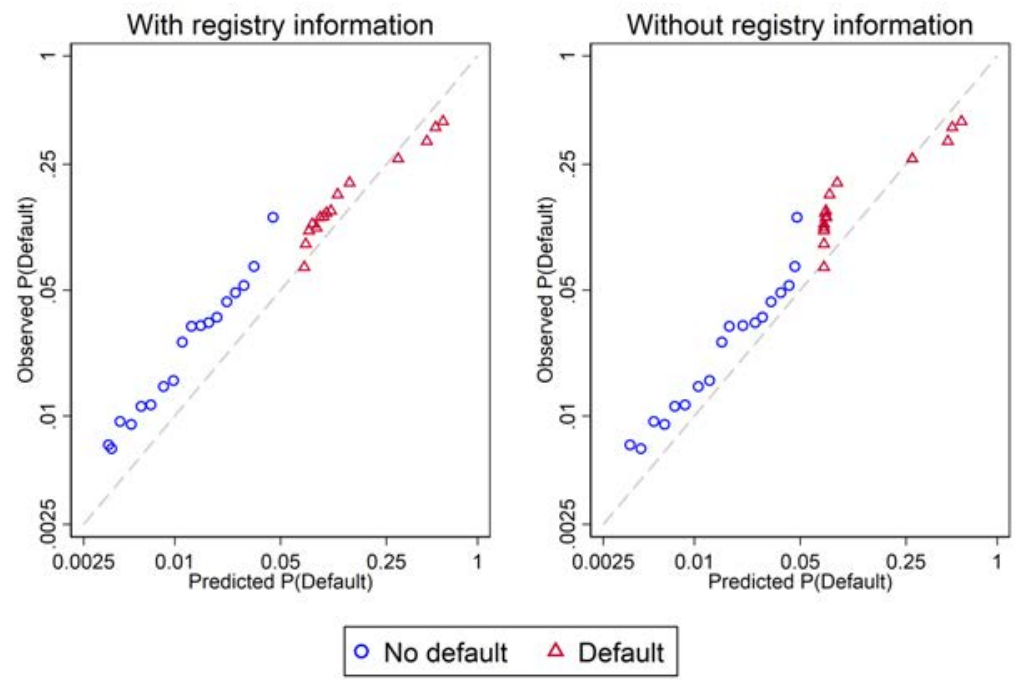

\begin{abstract}
Upper panel: binned means of random forest default predictions made without using registry data (vertical axis, log scale) by predicted value including registry data (horizontal axis, $\log$ scale). Bins are 20 quantiles of the distribution of full-information predictions for the no prior default and some prior default groups. 45-degree line plotted for convenience. Note that binned means are above the 45-degree line for no default group and below the line for default group. Lower panel: Binned means of random forest default predictions (horizontal axis; log scale) vs. out-of-sample observed default outcome (vertical axis, $\log$ scale). Left panel uses predictions that include registry information. Right panel uses predictions that exclude registry information. Our default outcome measure is an indicator variable for at least one new default in the six month period beginning in February 2012, the date of registry deletion. Predictions are constructed using registry and borrowing data from December 2009 and June 2010. See text for details.
\end{abstract}


Figure 6: Density of log exposure to information deletion

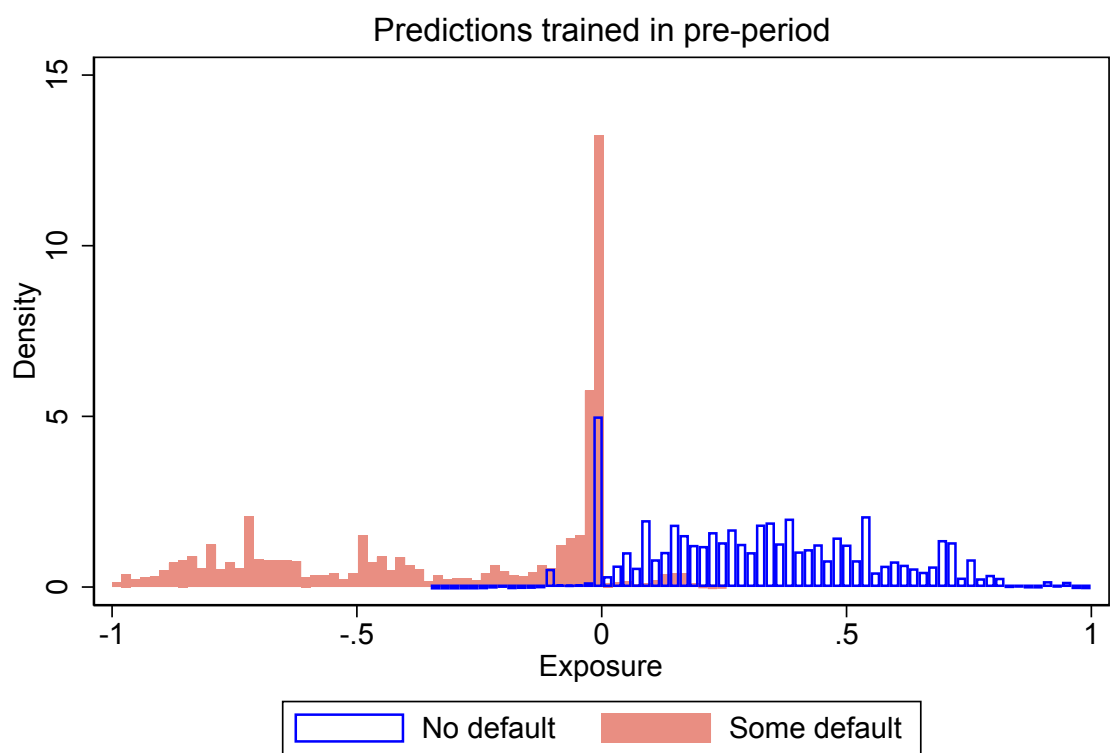

$99.2 \%$ of exposure data, December 2010 onwards

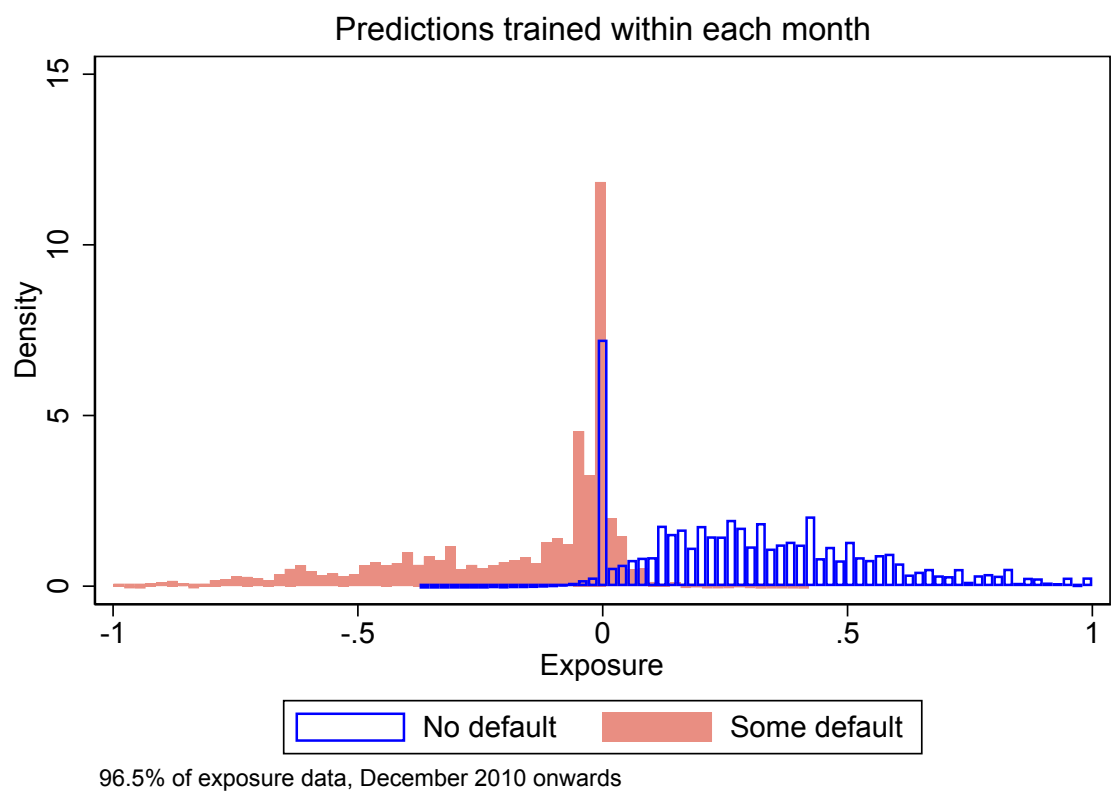

Histogram of changes in predicted log bank default by registry default status. Top: exposure generated from pre-period predictions. Bottom: exposure generated from contemporaneous predictions. Red bars is exposure for defaulters, blue for non-defaulters. Defaulter mean pre-period (contemporaneous) exposure is $-0.32(-0.17)$ and non-defaulter mean exposure is $0.33(0.34)$. Graphs show exposure distribution between -1 and 1 for each group. Sample: borrower panel from December 2010 through December 2011. 
Figure 7: Borrower SES and share of mortgage holders by exposure to information deletion
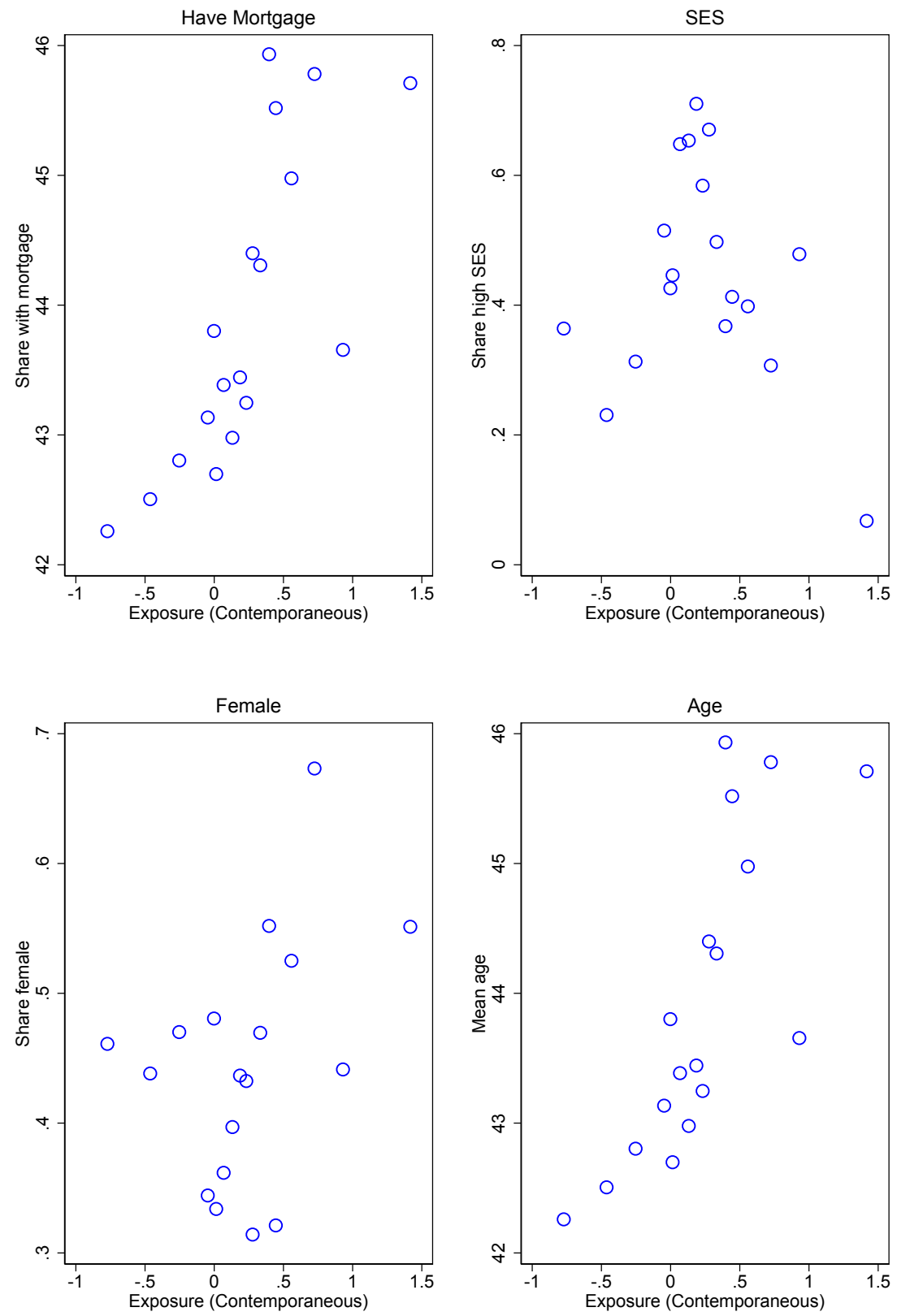

Binned means of indicators for having outstanding mortgage debt (left panel) and coming from a lowSES background (right panel) by decile of exposure distribution. Horizontal axis is log change in predicted default rate from deletion. ML predictions come from contemporaneous training dataset. 
Figure 8: Effects of registry deletion by exposure to changes in predicted default
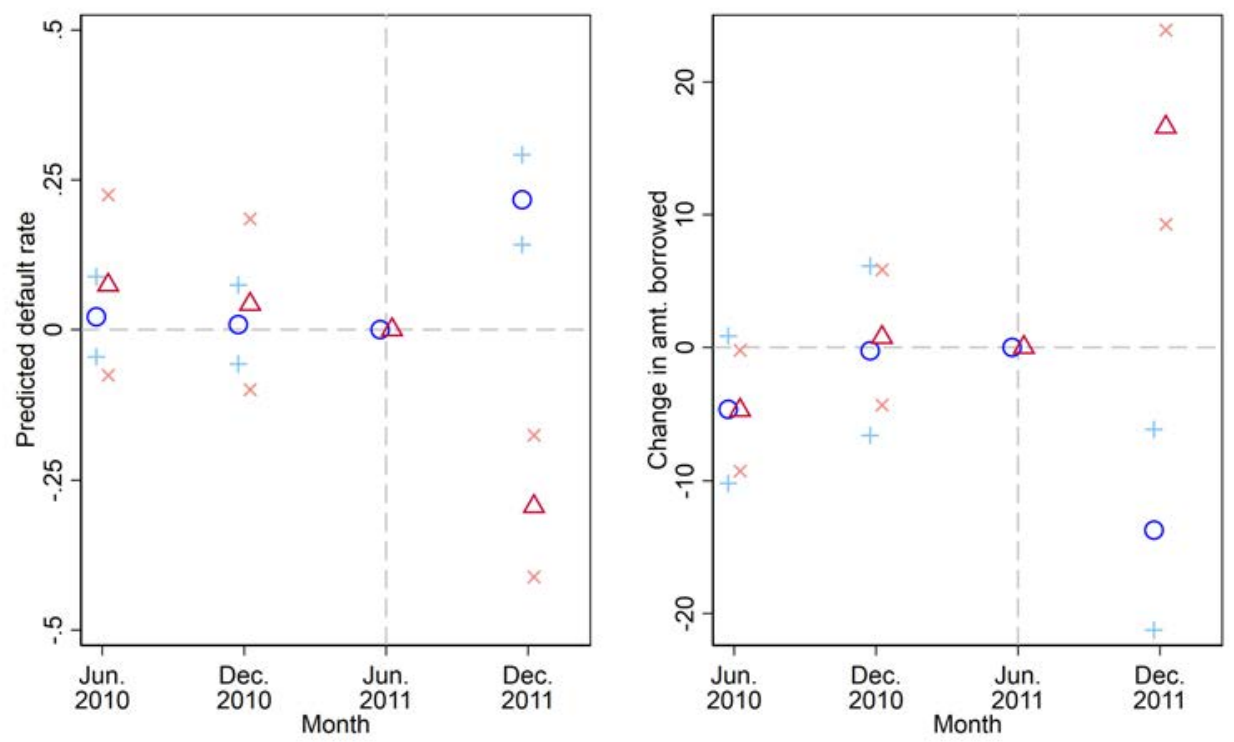

$$
\begin{array}{|l}
\hline \text { Positive exposure } \quad+95 \% \mathrm{Cl} \\
\triangle \text { Negative exposure } \quad \times 95 \% \mathrm{Cl}
\end{array}
$$

Difference-in-difference estimates and $95 \%$ CIs of the effects of exposure to changes in predicted default rate on predicted default rate (left panel) and new borrowing (right panel) using equation 1. Each panel splits the sample into individual with positive (high exposure) and negative (low exposure) changes in predicted default. Effects for each group are measured relative to the omitted category of no exposure to changes in predicted default, defined as the bottom fifteen percent of the distribution of the absolute value of predicted default changes. Standard errors clustered at market level. See text for details. 
Figure 9: Effects of registry deletion at the policy cutoff

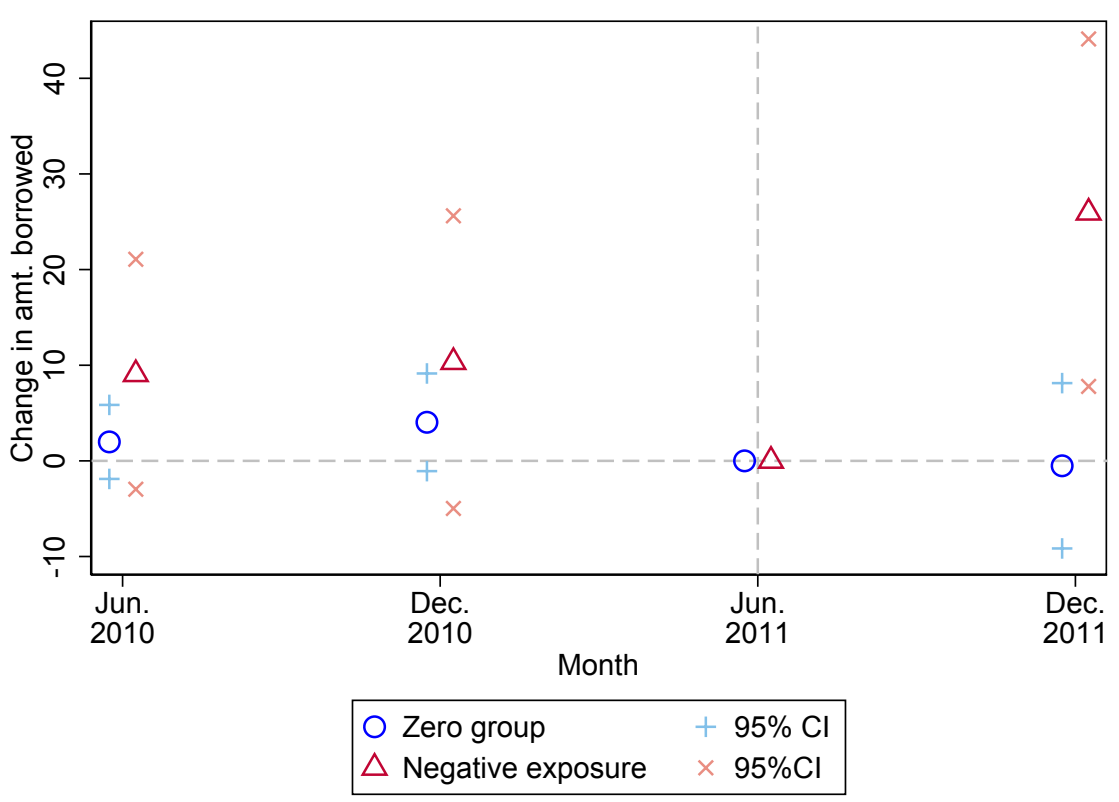

Difference-in-difference estimates and $95 \%$ confidence intervals for effects of the policy change at the policy cutoff of 2.5 million pesos using equation 2 for the exposure-defined 'zero group' and 'negative exposure'. Horizontal axis in each graph is time in six month intervals relative to the February 2012 deletion policy. These estimates compare new borrowing for individuals whose defaults are less than the cutoff relative to those whose defaults are higher than the cutoff, before and after the policy change, for the low exposure and zero groups.. Standard errors clustered at market level. See Section 3 for details. 
Figure 10: Effects of registry deletion by exposure and time relative to deletion

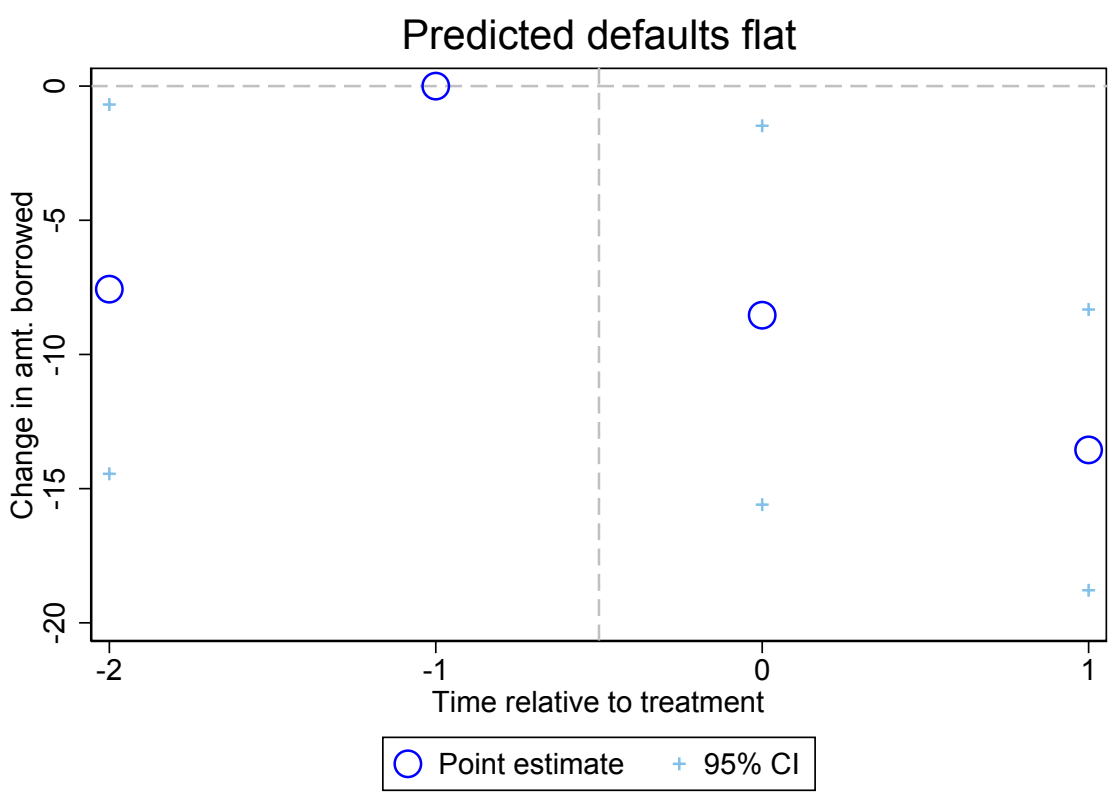

Difference-in-difference estimates and 95\% confidence intervals for effects of exposure to changes in borrowing using equation 3 for the exposure-defined 'zero group' only. Horizontal axis in each graph is time in six month intervals relative to the February 2012 deletion policy. These estimates work by comparing changes in borrowing pre- and post-February 2012 to changes pre- and post-February 2011. The 'Predicted default flat or zero group is the bottom $15 \%$ of the distribution of absolute values of changes in predicted default. Exposure is measured using December 2011 registry data in the 'treatment' sample and in December 2010 in the 'control' sample. Standard errors clustered at market level. See text for details. 
Figure 11: Equilibria for high- and low-cost markets and under pooling

\section{High-cost market}

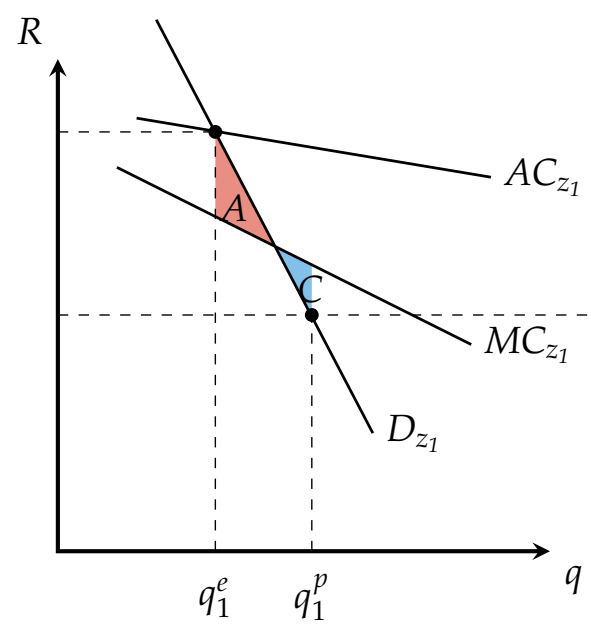

Low-cost market

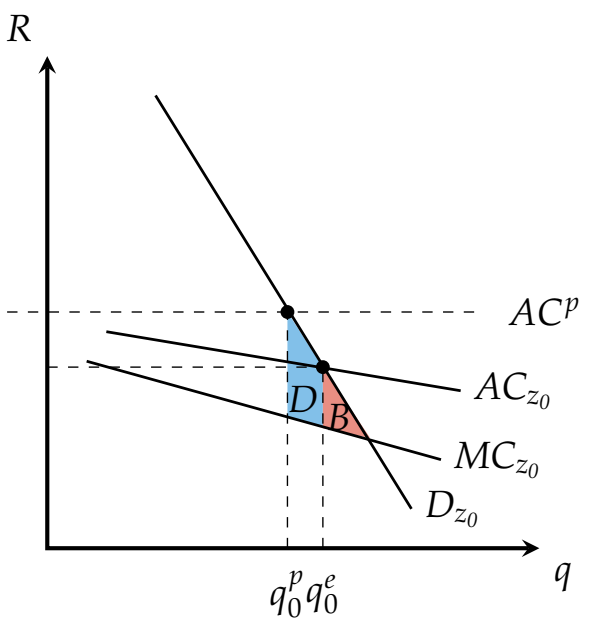

Diagram illustrating the economic framework. Left panel describes the high-cost market; right panel describes the low-cost market. 
Figure 12: Empirical estimates of different markets

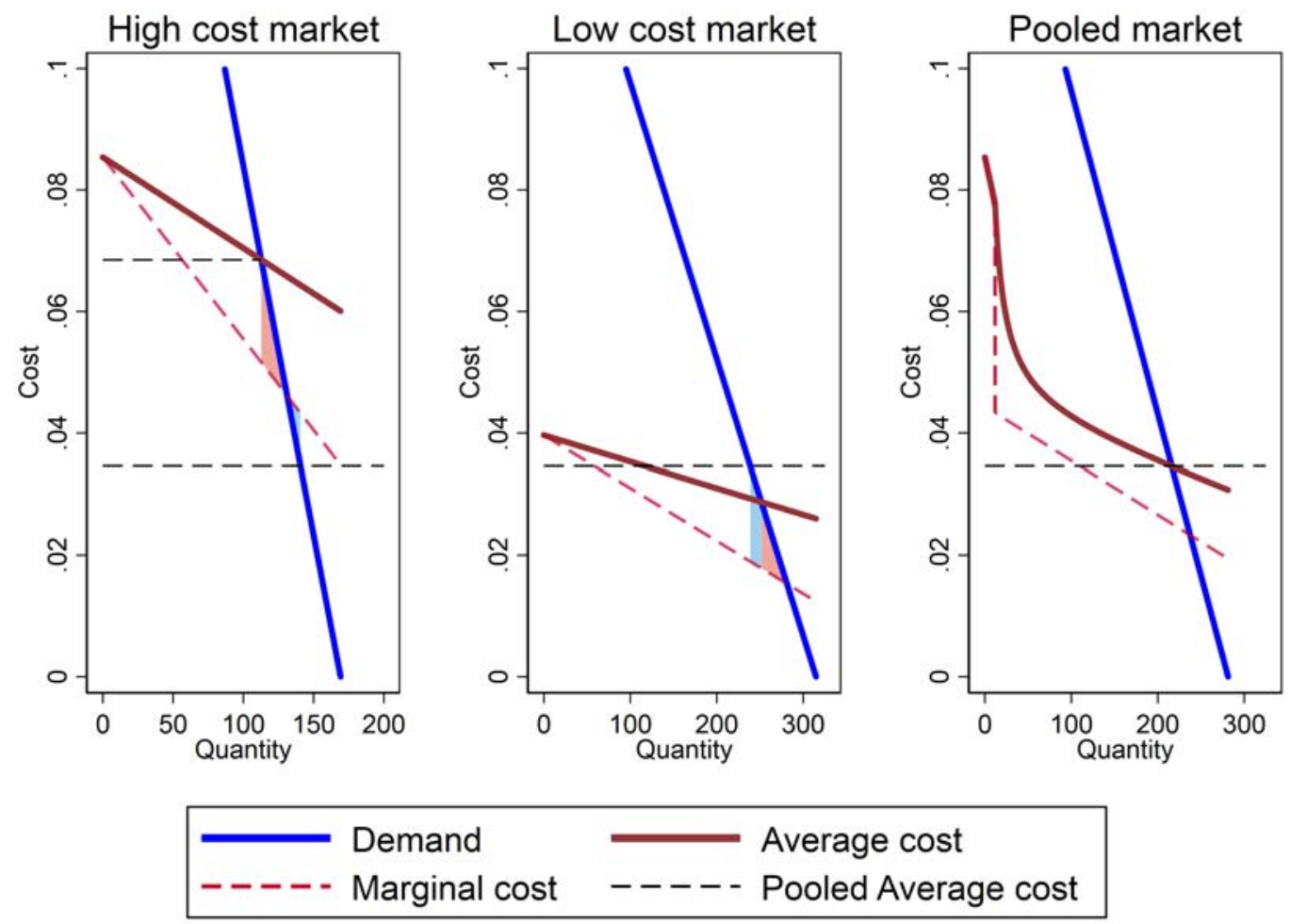

Empirical estimate of figure 11 using difference-in-difference estimates of slopes, assuming average cost pricing in both markets. See Section 3 for details. 
Figure 13: Heatmap describing surplus changes relative to baseline loss under different markup assumptions

\section{$\%$ change in welfare loss}

relative to baseline loss

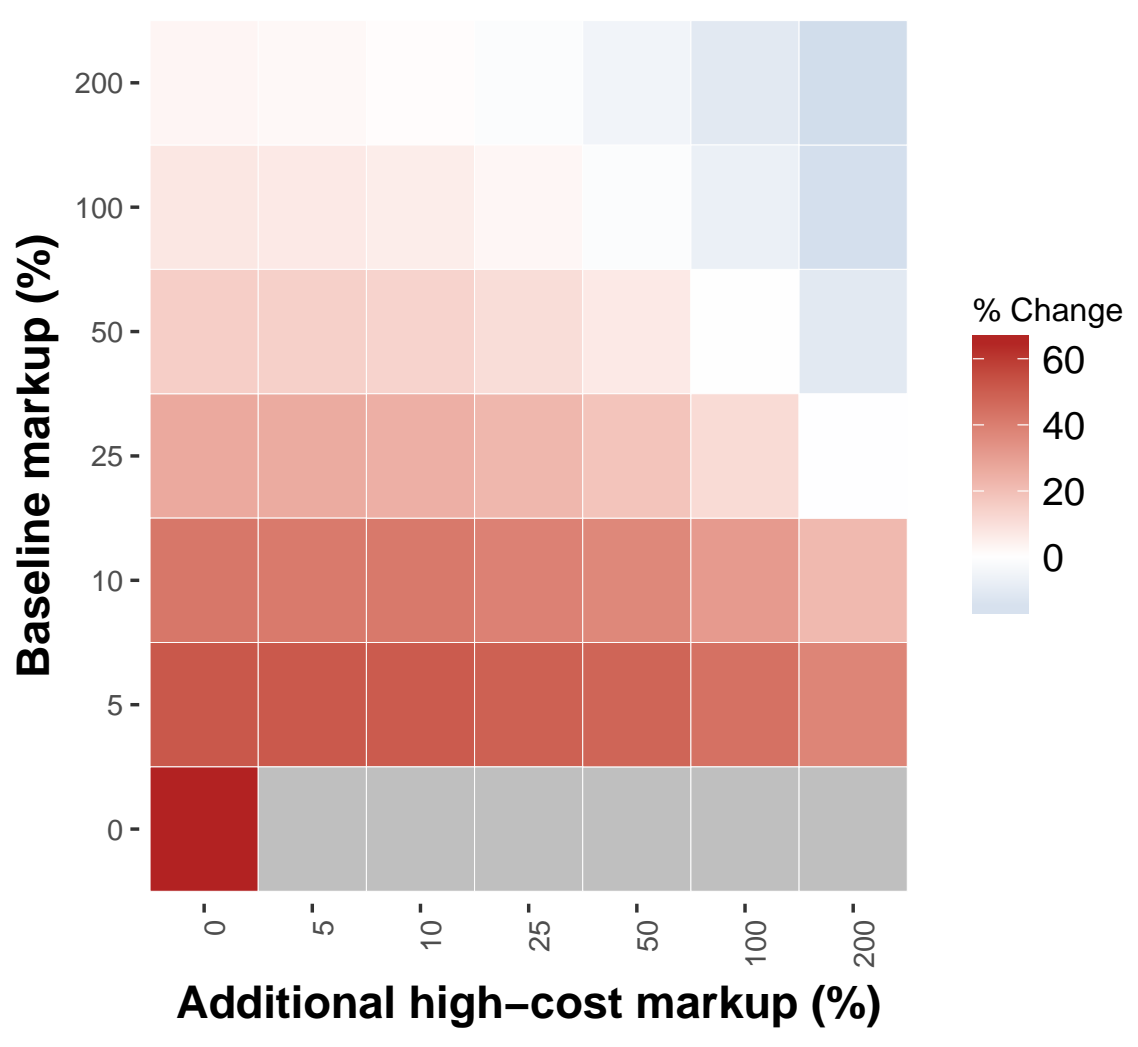

Percent changes in total surplus loss relative to baseline loss reported in Table 7 under different assumptions about markups in low- and high-cost markets. Surplus calculations described in section 4 . Vertical axis is markup at baseline in both high- and low-cost markets. Horizontal axis is additional markup in high-cost market. Average markups are constant before and after deletion. 
Figure 14: Distribution of exposure under counterfactual deletion policies

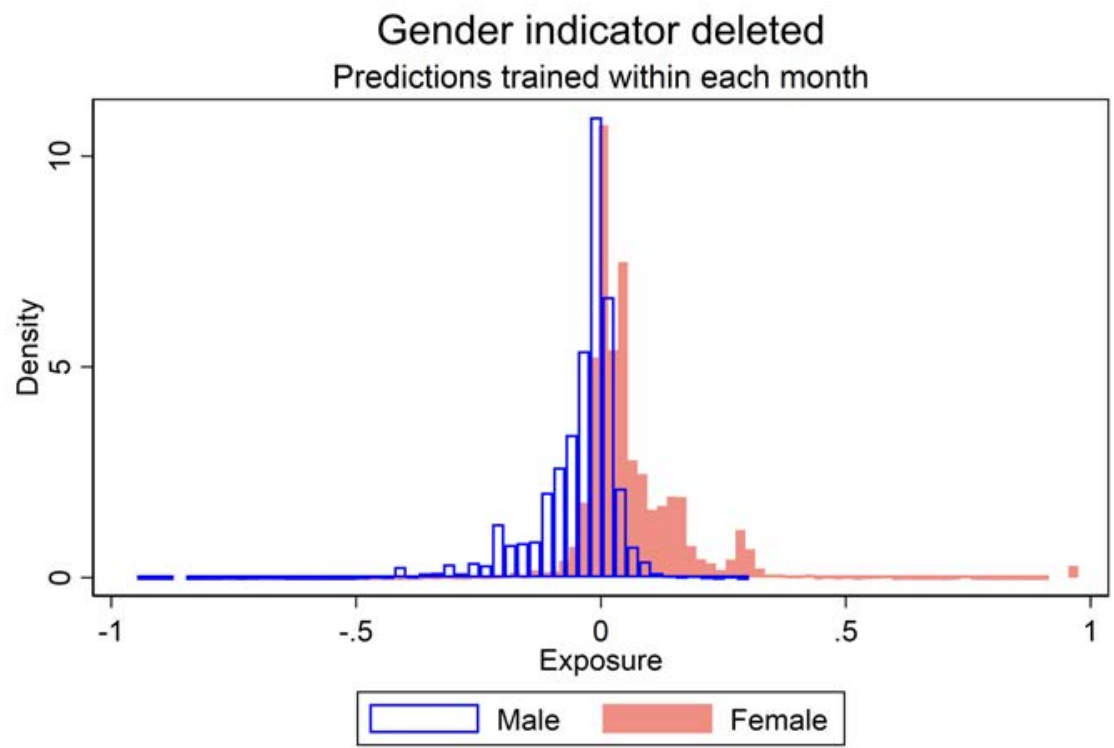

$100.0 \%$ of exposure data, December 2010 onwards

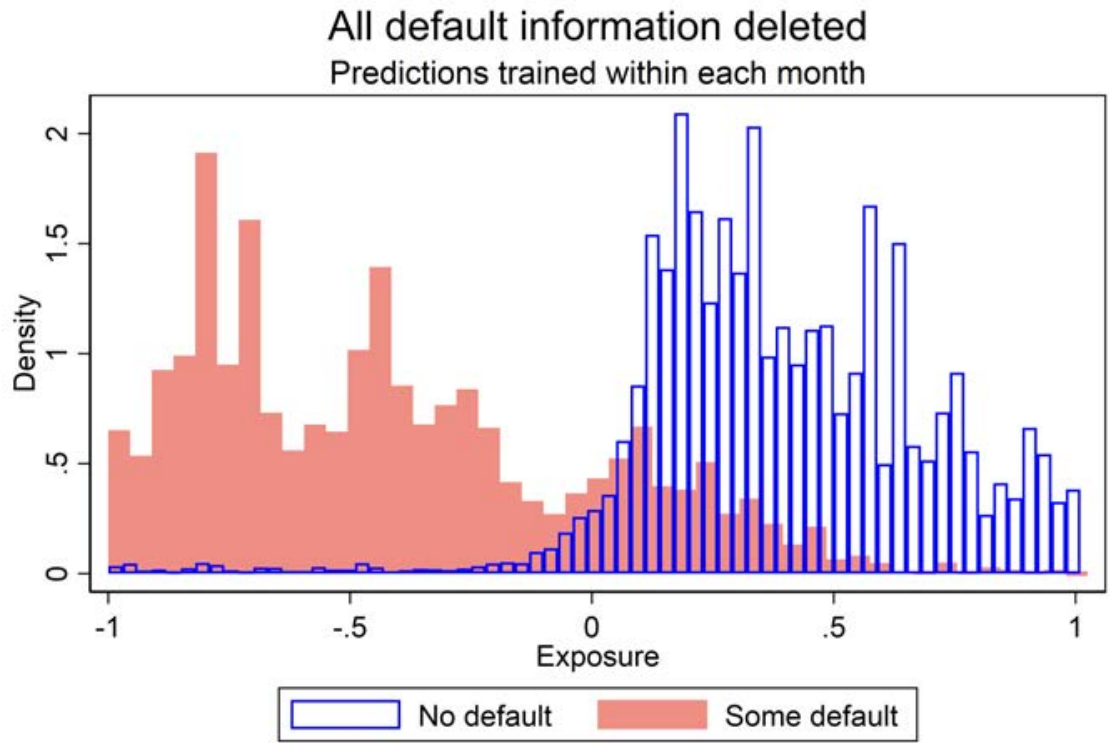

$78.0 \%$ of exposure data, December 2010 onwards

Histograms of exposure under counterfactual deletion policies. On top: log difference in prediced defaults ('exposure') excluding and including a gender indicator variable, split by gender. Below: exposure defined when all default information is deleted from the credit registry, split by default amout. See text for details. 
Table 1: Sample description

\begin{tabular}{|c|c|c|c|}
\hline & All & In Panel & $\begin{array}{c}\text { In Panel, } \\
\text { Positive Borrowing }\end{array}$ \\
\hline Any registry default & 0.37 & 0.33 & 0.14 \\
\hline Deletion eligible & 0.31 & 0.33 & 0.14 \\
\hline Observed deletion & 0.29 & 0.30 & 0.17 \\
\hline Registry default amt. & 554.50 & 182.00 & 54.45 \\
\hline Reg. default amt $\mid$ reg. $<2.5 \mathrm{~m}$ & 172.25 & 182.00 & 54.45 \\
\hline Debt balance & 7,768 & 7,675 & 13,075 \\
\hline Consumer borrowing balance & 2,172 & 2,097 & 2,634 \\
\hline Have mortgage & 0.19 & 0.19 & 0.24 \\
\hline Mortgage balance & 4,343 & 4,387 & 8,192 \\
\hline Any bank default & 0.17 & 0.14 & 0.03 \\
\hline Bank default amt. & 338.09 & 155.81 & 31.06 \\
\hline Bank default amt $\mid$ reg. $<2.5 \mathrm{~m}$ & 147.46 & 155.81 & 31.06 \\
\hline Default amt./balance & 0.12 & 0.09 & 0.01 \\
\hline New consumer borrowing & 0.31 & 0.32 & 1.00 \\
\hline New consumer borrowing amt. & 184 & 190 & 650 \\
\hline New bank default & 0.08 & 0.08 & 0.05 \\
\hline New bank default amt. & 36.57 & 27.28 & 14.55 \\
\hline Age & 44.12 & 44.08 & 43.40 \\
\hline Female & 0.44 & 0.45 & 0.45 \\
\hline Have SES & 0.10 & 0.10 & 0.13 \\
\hline SES A & 0.25 & 0.25 & 0.36 \\
\hline SES B & 0.29 & 0.29 & 0.27 \\
\hline SES C & 0.25 & 0.25 & 0.20 \\
\hline SES D \& E & 0.22 & 0.22 & 0.17 \\
\hline$N$ of observations & $23,001,337$ & $21,769,213$ & $4,593,511$ \\
\hline$N$ of clusters & 330 & 330 & 330 \\
\hline$N$ of individuals & $5,577,605$ & $5,433,403$ & $2,314,786$ \\
\hline
\end{tabular}

Descriptive statistics on borrowing sample. Observations are at the person by half-year level. Data run from August 2009 through July 2012. Six-month snapshots run from February-July and AugustJanuary. Borrowing outcomes from each six month interval are linked to credit registry data from two months prior to the start of the interval (December and June, respectively). We refer to time periods by the registry month. Columns define samples. 'All' column is all Chilean consumer bank borrowers. 'In panel' is the set of borrowers with a positive balance six months prior to a given month. 'In panel, positive borrowing' is the subset of borrowers who additionally have new borrowing in the snapshot a 10\% random sample of this subset defines our machine learning training set, which we exclude from the main panel. See text for details. 'Positive default' and 'Default (amt)' are dummies for positive registry defaults and mean default amount conditional on some positive value, respectively. 'Borrowing' is mean consumer borrowing balance. 'New borrowing' is an indicator variable equal to one if quarterly consumer balance expands by $10 \%$, and 'New borrowing, amt' is that indicator multiplied by the observed balance change. 'Debt,' 'New debt,' and 'New debt (amt)' are defined analogously but for all debt, including secured debt. SES categories are internal categorizations used by banks. 'Default amt./balance' are the share of debt at least 90 days overdue divided by the total debt balance. 
Table 2: Log Likelihoods of Various Algorithms

\begin{tabular}{lcccc}
\hline & \multicolumn{2}{c}{ Pre-period } & \multicolumn{2}{c}{ Contemporaneous } \\
& Training & Testing & Training & Testing \\
\hline Naive Bayes & & & & \\
With registry info & -0.412 & -0.682 & -0.398 & -0.633 \\
Without registry info & -0.324 & -0.516 & -0.300 & -0.458 \\
\hline Logistic LASSO & & & & \\
With registry info & -0.176 & -0.324 & -0.176 & -0.335 \\
Without registry info & -0.180 & -0.337 & -0.182 & -0.348 \\
\hline Random Forest & & & & \\
With registry info & -0.176 & -0.278 & -0.173 & -0.295 \\
Without registry info & -0.180 & -0.284 & -0.177 & -0.305 \\
\hline
\end{tabular}

Mean binomial log likelihoods for each algorithm. Columns identify the sample in which the log likelihood value is calculated. The 'training' sample is a $10 \%$ random sample of borrowers with new borrowing in the July 2009 Snapshot (pre-period) and within each snapshot (contemporaneous). 'Testing' identifies the main sample used in our analysis, from which the training set is dropped. Rows identify prediction methods. Within each prediction method, the 'with registy info' row uses registry information in addition to the other, while the 'without registry info' row does not. See section 3 for the full list of predictors and Appendix B for details on the transformation of these predictors and the structure of each algorithm. 
Table 3: Demographics by exposure category

\begin{tabular}{lcccc} 
& Positive exposure & Zero group & Negative exposure & Pooled \\
\hline Positive Default & 0.01 & 0.46 & 0.99 & 0.31 \\
Amt. Default & 52 & 696 & 456 & 566 \\
New Borrowing & 236 & 175 & 99 & 195 \\
New Debt & 468 & 356 & 156 & 384 \\
Positive Bank Default & 0.04 & 0.15 & 0.18 & 0.10 \\
Low SES & 0.50 & 0.56 & 0.71 & 0.55 \\
Have Mortgage & 0.25 & 0.18 & 0.18 & 0.22 \\
Age & 44.4 & 43.8 & 42.5 & 43.9 \\
Female & 0.47 & 0.41 & 0.46 & 0.45 \\
Share of individuals & 0.53 & 0.32 & 0.16 & 1 \\
$N$ & $2,051,138$ & $1,234,733$ & 612,737 & $3,898,608$ \\
\hline
\end{tabular}

Baseline borrowing and demographic characteristics by exposure-generated market type in July 2011. Rows correspond to features of the sample and columns define market type. 'Positive default' is an indicator for whether individuals have positive default balances within the snapshot while 'Amt. Default' computes the mean default value conditional on having positive default. 'New borrowing' computes mean new borrowing across all individuals, as does new 'New debt.' 'Positive bank default' indicates positives bank default for individuals within the snapshot. 'Low SES' is an indicator flagging bank defined socioeconomic status.' Have mortgage' is an indicator flagging whether individuals have positive mortgage balances in the snapshot. 'Age' reports the mean age of individuals in the snapshot in years. 'Female' is flags gender reported to the bank. Share of individuals computes the share of total individuals in the snapshot contained in each market, while $N$ reports the number of individuals (observations). 
Table 4: Difference in differences by default and exposure

\begin{tabular}{|c|c|c|c|c|}
\hline & \multicolumn{2}{|c|}{ Positive exposure } & \multicolumn{2}{|c|}{ Negative exposure } \\
\hline & $\begin{array}{c}\text { Predicted } \\
\text { Defaults }\end{array}$ & $\begin{array}{c}\text { New } \\
\text { Borrowing }\end{array}$ & $\begin{array}{c}\text { Predicted } \\
\text { Defaults }\end{array}$ & $\begin{array}{c}\text { New } \\
\text { Borrowing }\end{array}$ \\
\hline Jun. 2010 & $\begin{array}{c}0.02 \\
(0.03)\end{array}$ & $\begin{array}{c}-4.67^{+} \\
(2.81)\end{array}$ & $\begin{array}{c}0.07 \\
(0.08)\end{array}$ & $\begin{array}{c}-4.74^{*} \\
(2.30)\end{array}$ \\
\hline Dec. 2010 & $\begin{array}{c}0.01 \\
(0.03)\end{array}$ & $\begin{array}{l}-0.25 \\
(3.25)\end{array}$ & $\begin{array}{c}0.04 \\
(0.07)\end{array}$ & $\begin{array}{c}0.75 \\
(2.59)\end{array}$ \\
\hline Jun. 2011 & $\begin{array}{c}0.00 \\
(0.00)\end{array}$ & $\begin{array}{c}0.00 \\
(0.00)\end{array}$ & $\begin{array}{c}0.00 \\
(0.00)\end{array}$ & $\begin{array}{c}0.00 \\
(0.00)\end{array}$ \\
\hline Dec. 2011 & $\begin{array}{c}0.22^{* * *} \\
(0.04)\end{array}$ & $\begin{array}{c}-13.72^{* * *} \\
(3.83)\end{array}$ & $\begin{array}{c}-0.29^{* * *} \\
(0.06)\end{array}$ & $\begin{array}{c}16.60^{* * *} \\
(3.72)\end{array}$ \\
\hline Elasticity & & -0.29 & & -0.40 \\
\hline Dep. Var. Base Period Mean & 0.04 & 215.28 & 0.10 & 140.98 \\
\hline N Clusters & 303 & 303 & 282 & 285 \\
\hline N Obs. & $2,910,733$ & $13,093,725$ & $1,273,371$ & $7,493,968$ \\
\hline$N$ Individuals & $1,836,294$ & $4,363,940$ & 986,205 & $3,212,628$ \\
\hline$N$ Exposed Individuals & 505,295 & $2,132,055$ & 84,746 & 608,229 \\
\hline
\end{tabular}

Significance: ${ }^{+} 0.10^{*} 0.05^{* *} 0.01 * * * 0.001$. Difference and difference estimates from equation 1 . The first two columns report the difference-in-difference estimated effect of deletion on outcome variables listed in column headers, while the third and fourth estimate the dif-in-dif effect on the different exposure-defined markets. Sample in specifications where cost is an outcome conditions on positive borrowing (see text for details). We take the log of 'Predicted Default' for estimation but report the base period mean in levels. 'Elasticity' is borrowing effect scaled by base period outcome mean and predicted default effect. ' $\mathrm{N}$ exposed individuals' reports the number of individuals not in the 0 group included in the regression sample in the treatment period. Since some individuals appear in multiple snapshots we report both individuals and observations. Standard errors clustered at market level. See text for details. 
Table 5: Difference in differences by exposure, mortgage, and socioeconomic status

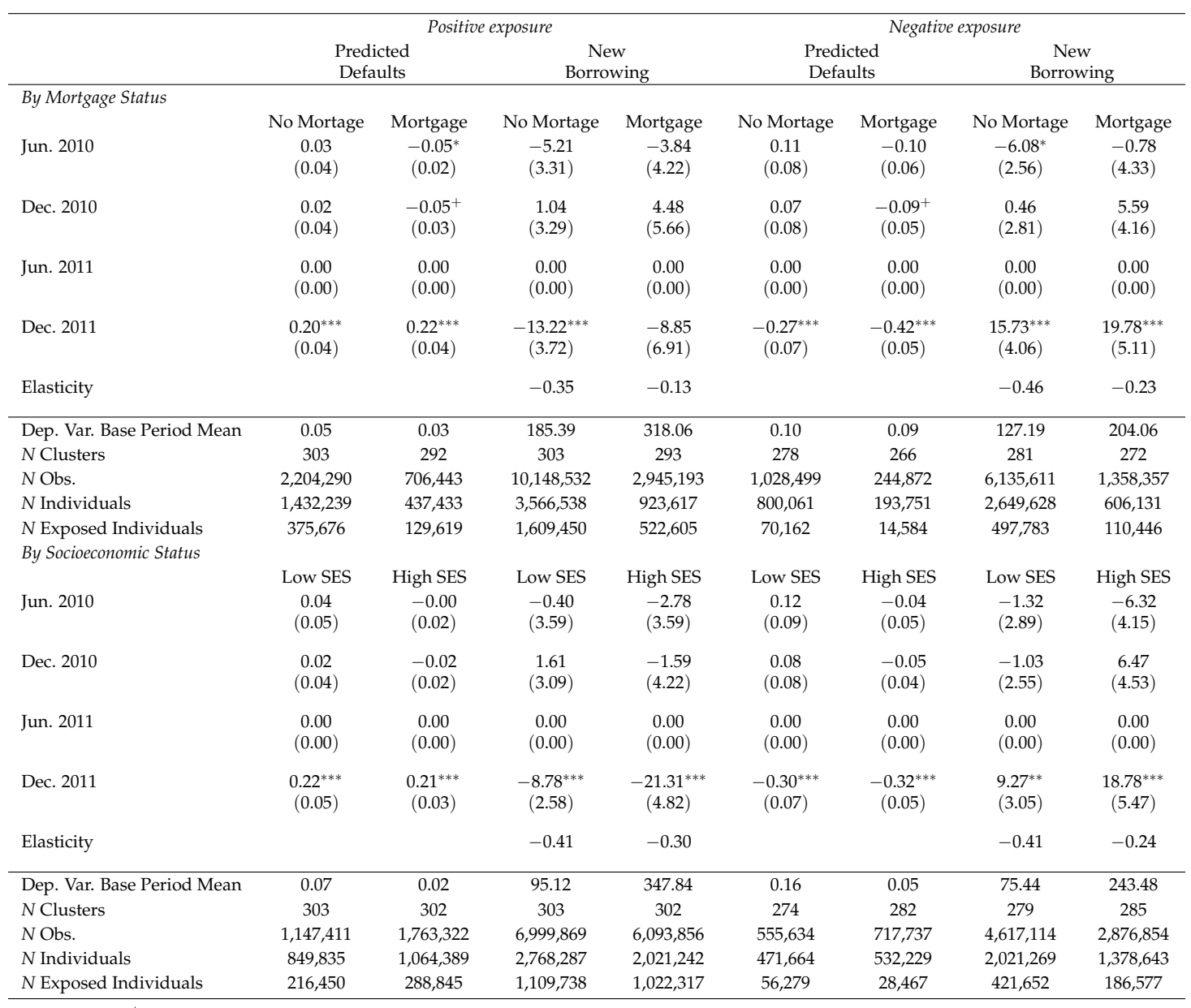

Significance: ${ }^{+} 0.10^{*} 0.05^{* *} 0.01^{* * *} 0.001$.Difference in difference estimates from equation 1 over defined subsamples. Columns 1 through 4 are predicted default and borrowing diff-in-diff effect estimates in the high exposure market while columns 5 through 8 report estimates in the low exposure market. Column headers report dependent variable at the top and subsample below. Sample in specifications where default is an outcome conditions on positive borrowing (see text for details). Elasticity is borrowing effect scaled by base period outcome mean and predicted default effect within each market-subsample. We take the log of 'Predicted Default' for estimation but report the base period mean in levels. ' $N$ exposed individuals reports the number of individuals not in the 0 group included in the regression sample in the treatment period. Since some individuals appear in multiple snapshots we report both individuals and observations. Standard errors clustered at market level. See text for details. 


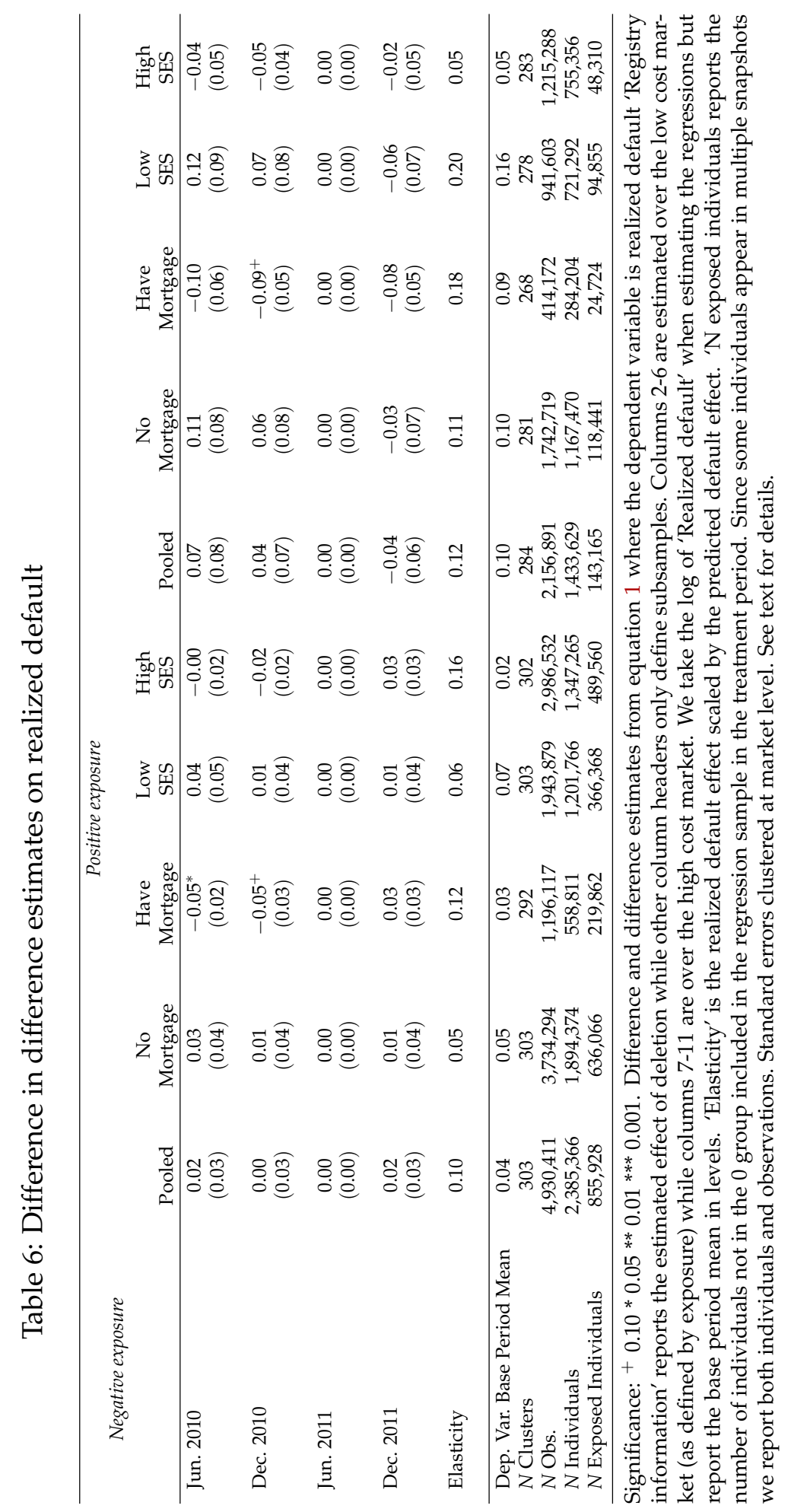


Table 7: Distribution of deletion effects

\begin{tabular}{|c|c|c|c|}
\hline & Separate & Pooled & Difference \\
\hline \multicolumn{4}{|l|}{ Positive exposure } \\
\hline Predicted cost & 0.029 & 0.035 & 0.006 \\
\hline Average cost & 0.029 & 0.029 & 0.001 \\
\hline New borrowing (1000s CLP) & 251.561 & 238.714 & -12.847 \\
\hline Surplus loss (1000s CLP) & 0.161 & 0.331 & 0.170 \\
\hline Aggregate new borrowing (Bns CLP) & 516 & 490 & -26 \\
\hline Aggregate surplus loss (1000s CLP) & 330,480 & 679,717 & $\begin{array}{l}349,238 \\
105.68 \%\end{array}$ \\
\hline$N$ individuals & $2,051,138$ & $2,051,138$ & $2,051,138$ \\
\hline \multicolumn{4}{|l|}{ Negative exposure } \\
\hline Predicted cost & 0.069 & 0.035 & -0.034 \\
\hline Average cost & 0.069 & 0.064 & -0.004 \\
\hline New borrowing (1000s CLP) & 112.713 & 140.695 & 27.981 \\
\hline Surplus loss (1000s CLP) & 0.156 & 0.041 & -0.114 \\
\hline Aggregate new borrowing (Bns CLP) & 69 & 86 & 17 \\
\hline Aggregate surplus loss (1000s CLP) & 95,456 & 25,307 & $\begin{array}{l}-70,149 \\
-73.49 \%\end{array}$ \\
\hline$N$ individuals & 612,737 & 612,737 & 612,737 \\
\hline \multicolumn{4}{|l|}{ Combined } \\
\hline Average cost & 0.033 & 0.035 & 0.001 \\
\hline New borrowing (1000s CLP) & 219.624 & 216.168 & -3.455 \\
\hline Surplus loss (1000s CLP) & 0.160 & 0.265 & $\begin{array}{c}0.105 \\
65.52 \%\end{array}$ \\
\hline Aggregate new borrowing (Bns CLP) & 585 & 576 & -9 \\
\hline Aggregate surplus loss (1000s CLP) & 425,936 & 705,025 & $\begin{array}{c}279,089 \\
65.52 \%\end{array}$ \\
\hline$N$ individuals & $2,663,875$ & $2,663,875$ & $2,663,875$ \\
\hline
\end{tabular}

This table describes changes in key metrics before and following deletion. Prices and surplus calculations assume average cost pricing. See text for details. 'Positive exposure' panel is individuals whose predicted defaults rise following deletion; 'Negative exposure' is individuals whose predicted defaults fall. 'Combined' panel averages over both markets for prices, average cost, new borrowing, and surplus measures, while summing for aggregate borrowing/surplus measures. 'New borrowing' in 1000s of CLP. Aggregate new borrowing is in billions of CLP. 
Table 8: Effects of counterfactual exposure policies

\begin{tabular}{|c|c|c|c|c|}
\hline & $\begin{array}{c}\text { Exposed to } \\
\text { predicted default } \\
\text { increases }\end{array}$ & $\begin{array}{c}\text { Zero } \\
\text { group }\end{array}$ & $\begin{array}{c}\text { Exposed to } \\
\text { predicted default } \\
\text { decreases }\end{array}$ & Pooled \\
\hline \multicolumn{5}{|l|}{ Gender indicator deleted } \\
\hline Exposure to cost increases & 0.24 & 0.00 & -0.25 & 0.00 \\
\hline Positive Default & 0.00 & 0.34 & 0.00 & 0.36 \\
\hline Amt. Default & 479 & 571 & 71 & 1,621 \\
\hline New Borrowing & 63 & 184 & 81 & 168 \\
\hline New Debt & 203 & 369 & 106 & 337 \\
\hline Positive Bank Default & 0.02 & 0.10 & 0.04 & 0.10 \\
\hline Low SES & 0.18 & 0.22 & 0.17 & 0.22 \\
\hline Have Mortgage & 0.08 & 0.21 & 0.12 & 0.20 \\
\hline Age & 45.3 & 43.9 & 45.5 & 44.1 \\
\hline Female & 0.98 & 0.44 & 0.16 & 0.45 \\
\hline Share of individuals & 0.04 & 0.87 & 0.04 & 1 \\
\hline$N$ & 171,878 & $4,111,244$ & 166,565 & $4,721,885$ \\
\hline \multicolumn{5}{|l|}{ All default information deleted } \\
\hline Exposure to cost increases & 0.63 & 0.06 & -0.84 & 0.15 \\
\hline Positive Default & 0.07 & 0.18 & 0.93 & 0.36 \\
\hline Amt. Default & 460 & 432 & 602 & 1,621 \\
\hline New Borrowing & 135 & 535 & 77 & 168 \\
\hline New Debt & 307 & 985 & 128 & 337 \\
\hline Positive Bank Default & 0.06 & 0.08 & 0.20 & 0.10 \\
\hline Low SES & 0.22 & 0.16 & 0.26 & 0.22 \\
\hline Have Mortgage & 0.22 & 0.18 & 0.18 & 0.20 \\
\hline Age & 44.4 & 45.2 & 42.5 & 44.1 \\
\hline Female & 0.46 & 0.43 & 0.44 & 0.45 \\
\hline Share of individuals & 0.55 & 0.13 & 0.25 & 1 \\
\hline$N$ & $2,615,689$ & 630,130 & $1,203,868$ & $4,721,885$ \\
\hline
\end{tabular}

Baseline borrowing and demographic characteristics by exposure-generated market type in July 2011 under counterfactual policy changes. Panels are separated by counterfactual policy: deleting a gender indicator variable and deleting all default information. Rows correspond to features of the sample and columns define market type. 'Positive default' is an indicator for whether individuals have positive default balances within the snapshot while 'Amt. Default' computes the mean default value conditional on having positive default. 'New borrowing' computes mean new borrowing across all individuals, as does new 'New debt.' 'Positive bank default' indicates positives bank default for individuals within the snapshot. 'Low SES' is an indicator flagging bank defined socioeconomic status.' Have mort-

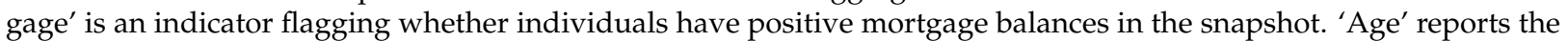
mean age of individuals in the snapshot in years. 'Female' is flags gender reported to the bank. Share of individuals computes the share of total individuals in the snapshot contained in each market, while $N$ reports the number of individuals (observations). 